Historical review

\section{Francisco Campos-Rivadeneira and Roberto Levi- Castillo: Their lives and contributions to the study of mosquitoes (Diptera: Culicidae) in Ecuador}

\author{
Giovani Marcelo Ramón ${ }^{1,2}$, Rodolfo Pérez ${ }^{3}$, Pablo Jarrín ${ }^{4}$ \\ ${ }^{1}$ Museo de Zoología, Instituto de Zoología Terrestre, Colegio de Ciencias Biológicas y \\ Ambientales, Universidad San Francisco de Quito, Quito, Ecuador \\ ${ }^{2}$ Instituto Biosfera, Colegio de Ciencias Biológicas y Ambientales, Universidad San Francisco de \\ Quito, Quito, Ecuador \\ ${ }^{3}$ Academia Nacional de Historia del Ecuador, Quito, Ecuador \\ ${ }^{4}$ Universidad Regional Amazónica Ikiam, Tena, Ecuador \\ The study of mosquitoes is important in the prevention of vector-borne diseases. In \\ Ecuador, the study of local mosquito biodiversity was pioneered by two entomologists \\ whose contributions span through the first half of the $20^{\text {th }}$ century, Francisco Campos- \\ Rivadeneira and Roberto Levi-Castillo. \\ Both of them contributed to general aspects of Entomology and to particular insights in \\ mosquito taxonomy. Their publications and discoveries were recognized by the international \\ scientific community but went unnoticed in South America during their time. Today, very few \\ citizens remember the names and contributions of these two scientists. \\ Here, we provide an overview of their lives, a summary of their contributions, and we \\ conclude with a broader outlook on the practice of science in Latin America during their time.
}

Keywords: Culicidae/classification; disease vectors; entomology/history; Ecuador.

Francisco Campos-Rivadeneira y Roberto Levi-Castillo: sus vidas y contribuciones al estudio de los mosquitos (Diptera: Culicidae) en Ecuador

El estudio de los mosquitos es una importante tarea en la prevención de las enfermedades transmitidas por vectores. En Ecuador, el conocimiento de la biodiversidad local de mosquitos se inició con dos entomólogos pioneros que trabajaron a inicios del siglo XX: Francisco Campos-Rivadeneira y Roberto Levi-Castillo.

Ambos hicieron importantes contribuciones en el campo de la Entomología en general y de la taxonomía de los mosquitos en particular. En su época, sus aportes fueron reconocidos por la comunidad científica internacional, pero pasaron desapercibidos en la región suramericana. Hoy en día, son muy pocos los que recuerdan los nombres y los aportes de estos dos hombres de ciencia.

En este artículo, se presenta una breve biografía de ambos científicos y un resumen de sus contribuciones, y se establece en perspectiva la situación de la práctica de la ciencia en Latinoamérica durante la época.

Palabras clave: Culicidae/clasificación; vectores de enfermedades; entomología/historia; Ecuador.

The study of mosquito populations and their distribution is an important component in the prevention of vector-borne diseases. This is particularly important nowadays given the increasing frequency of mosquito-transmitted diseases and the emergence of new arboviruses (for example, chikungunya, Zika) (1-5).

The seminal contributions of Roberto Levi-Castillo and Francisco CamposRivadeneira (Levi-Castillo R. Provisional List of the Culicidae, Simuliidae, Phlebotomus, and Culicoides of Ecuador. Proceedings, Tenth International Congress of Entomology, Montreal, August 17-25, 1956. Section on Medical and Veterinary Entomology. 1958, Vol. 3, p. 867-71) (6-8) remained isolated and inactive in the timeline of mosquito vector research in Ecuador for an extended period. The study of mosquitoes in Ecuador has regained attention with both ecological (9-15) and taxonomic studies (16-19) only recently.

The current estimated number of mosquito (Diptera: Culicidae) species in Ecuador is 244 (12,17,20-22). However, this estimate is expected to increase 


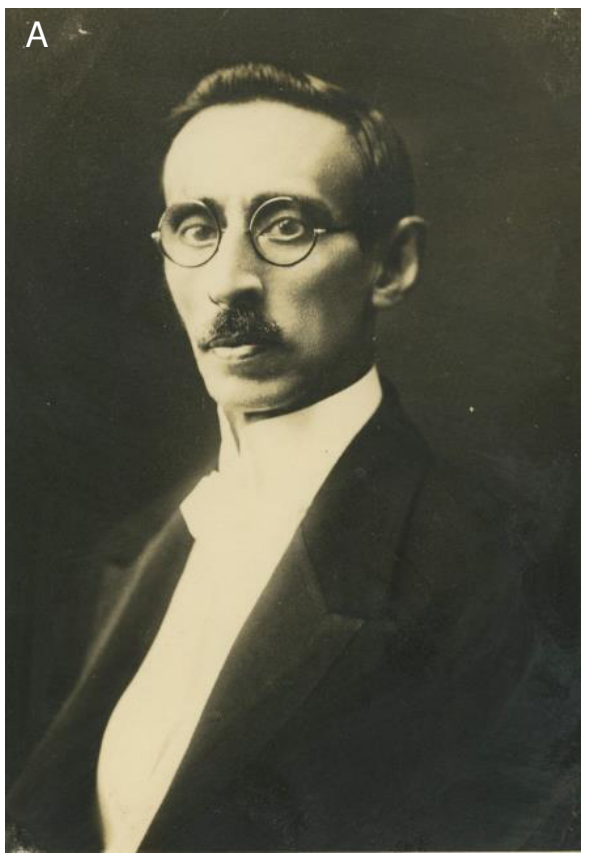

in the next few years given the sustained efforts of local researchers to explore the ample diversity of habitats and complex geography of Ecuador $(23,24)$. This process of discovery will be accelerated by the availability of new molecular methods that allow differentiating what once were cryptic and unknown mosquito species $(18,25,26)$.

Both entomologists, Francisco Campos-Rivadeneira (figure 1A) and Roberto Levi-Castillo (figure 1B), were born in the port city of Guayaquil and they pioneered the study of mosquito vectors and established the seeds for the development of Medical Entomology in Ecuador during the $20^{\text {th }}$ century (8). Although the works of these pioneering entomologists have been acknowledged to some extent in a handful of publications $(8,12)$, no complete assessment has been made on the scientific efforts and contributions of these two Ecuadorian scientists, especially in regards to our understanding of mosquito biodiversity and taxonomy.

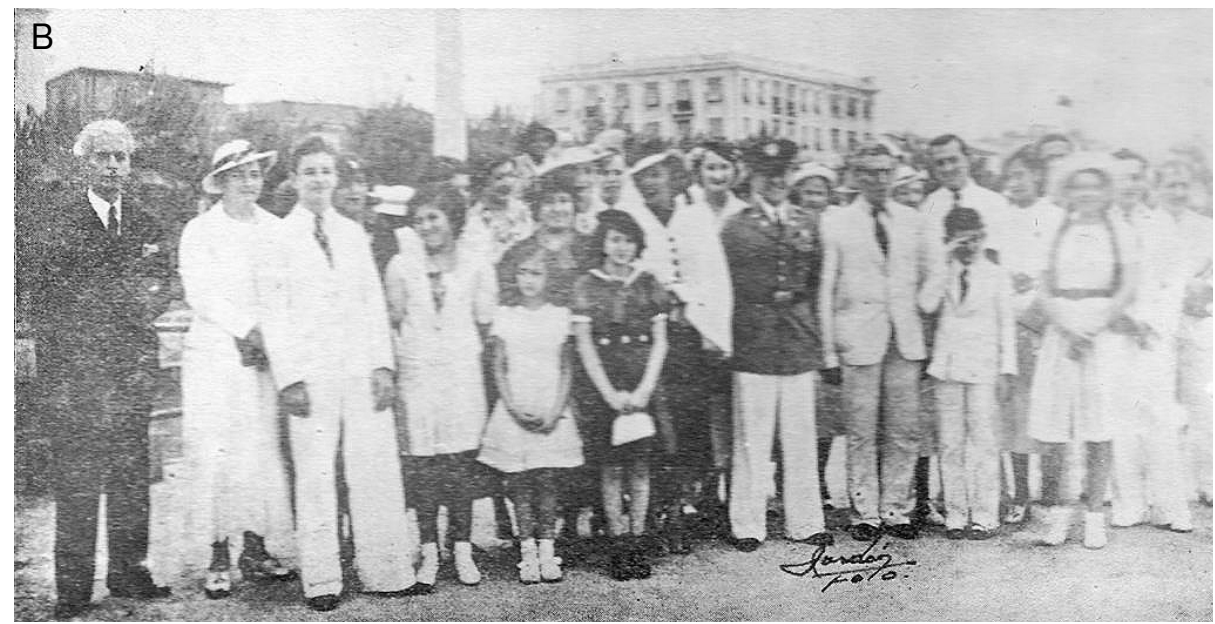

Figure 1. A. Portrait of Francisco Campos-Rivadeneira in 1935

Reproduction authorized by: Archivo Histórico Camilo Destruge, Biblioteca Municipal de Guayaquil, Instituto Nacional de Patrimonio Cultural del Ecuador).

B. Picture of a young Roberto Levi-Castillo (third from the left) in Guayaquil after his arrival from the United States in 1938.

Reproduction authorized by: Archivo Histórico del Ministerio de Cultura y Patrimonio del Ecuador

Here we provide a biography and historical assessment on the lives of these two Ecuadorian scientists and we provide a comprehensive list of the scientific literature regarding their entomological studies, in particular, their contributions to the study of mosquitoes in Ecuador. We believe the lives of both Ecuadorian entomologists can serve as a case study on the cultural and economic conditions in Ecuador and other countries in South America, which throughout the $20^{\text {th }}$ century experienced a unique and difficult history for the development of science. The system proposed by Reinert (27) for abbreviations of mosquito generic-level taxa is used throughout the text.

\section{Francisco Campos-Rivadeneira}

Campos-Rivadeneira was born in Guayaquil, in the province of Guayas (coastal Ecuador), on January $11^{\text {th }}, 1879$. His father was Francisco Campos Coello and his mother Manuela Rivadeneira Olvera. He grew up in a catholic and traditional family along with six other siblings and he never completed high school $(28,29)$. His father's family had a long tradition of intellectuals, 
which included physicians, bibliographers, and antiquarians. His father was an outstanding humanist and thinker of his time, who held important academic and political positions throughout his life, including director of the Biblioteca Municipal in Guayaquil, secretary of the Banco Nacional, head of Guayaquil's most important high school, minister of Education, professor, journalist, and politician (30).

From an early age and encouraged by his father, Campos-Rivadeneira developed a strong interest in the natural world. He and his father used to take long excursions through Guayaquil and its rural outskirts, where they would look for all kinds of animals, particularly insects. Given his shy and introverted personality, a young Campos-Rivadeneira spent most of his time collecting insects and learning from books. Having left aside formal instruction, his love for insects drove him to acquire knowledge on the principles of Entomology and other scientific disciplines. Given the social limitations of his time and society, Campos-Rivadeneira self-taught scientific mastery on Entomology was remarkable. At only 16 years of age, he was hired to teach geography at the Colegio Nacional Vicente Rocafuerte $(28,29)$. $\mathrm{He}$ also received instruction from the Jesuit priest Luis Sodiro, who was a renowned botanist, and from whom Campos-Rivadeneira probably acquired much of his curiosity for nature (31).

In 1895, after the liberal revolution in Ecuador (32), his father was given the position of principal at the Colegio San Vicente del Guayas. From this new position, his father established the Museo de Ciencias Naturales and bought a collection of zoological, botanical, and mineralogical specimens from France. Endorsed by his father, Campos-Rivadeneira was soon appointed as museum director. This academic position may have given CamposRivadeneira an adequate environment to further his interests in the study of insects and allowed him to house his private collections into the museum he directed, which included beetles and a large variety of metals and precious stones. In 1899, he started editing a "Guía rápida del museo" which included information on insects. He wished to share the love and admiration he had for the local fauna with the citizens of Guayaquil (29).

In 1900, after publishing an article on Ecuadorian entomology, he was invited to the Latin American Scientific Conference in Buenos Aires. Tragically, a year later the museum collections under his aegis were destroyed in a fire that burned to ashes most of the Colegio Nacional Vicente Rocafuerte. Despite this setback, Campos-Rivadeneira continued making expeditions and publishing the results of his findings. Considering his efforts to elevate national science, president Lizardo García awarded him the title of "Zoólogo del Estado". The museum was re-opened after a year of inactivity following the fire $(28,29)$.

In 1902, he was appointed as professor of Natural Sciences and lectured on the subject of Hygiene at the Facultad de Medicina of the Universidad de Guayaquil. He was a kind and inspiring professor who soon became popular among his students, especially during the entomological expeditions that he liked to share with his pupils. His publications on Entomology started to appear more frequently on local magazines, which remain as historical proof of his expertise on a wide range of entomological groups (for example, butterflies, crickets, and beetles) and fields in the natural sciences (taxonomy, morphology, and behavior, among others). In 1907, his sustained contributions to Ecuadorian entomology granted him a membership to the Entomological Society of Cornell, Pennsylvania (28). 
From 1907 onwards, most of his studies focused on agricultural pests and in 1917, he was recognized as a member of the Entomological Society of America. In 1920, his interest on medical entomology strengthened and he edited a book entitled "Entomología médica: nuestras principales especies de mosquitos y el modo de extinguirlas". This book is considered a pioneering effort to inform the local population of Ecuador about the risks of malaria and its vectors. This was followed by a publication on the mosquito fauna of Guayaquil and its surroundings (7). In 1926, he was visited by Emilio J. Pampana, a physician from the Royal College of Physicians and Surgeons of London, with whom he edited a paperback on the anti-malaria campaign in Guayaquil. In 1940, due to his scientific trajectory and productivity, he was appointed Chief of the Servicio Entomológico at the Instituto Nacional de Higiene (currently known as Instituto Nacional de Investigaión en Salud Pública Leopoldo Izquieta Pérez), a position that he held until the last days of his life $(28,29)$.

Campos-Rivadeneira had a prolific career and collaborated with many foreign researchers in the field of Entomology. His network of collaborators is exemplified on the many taxa that have been named after him, such as the genus Camposiana Townsend 1915 (Diptera: Tachinidae), Camposiella Hebard 1924 (Orthoptera: Tettigoniidae), and Campostrecha Mello Leitão 1937 (Arachnida: Ammostrechidae), a species of water strider, Hebrus camposi (Hemiptera: Hebridae) (33), as well as many species of tiger beetles $(34,35)$. Most of his articles were published in the Revista del Colegio Nacional Vicente Rocafuerte $(36,37)$.

The prints of this magazine are few and rare nowadays, held only in a few century-old universities in Ecuador and the central archives of the Ecuadorian government. In an enjoyable quirk of history, Campos-Rivadeneira wrote an article on Morpho butterflies in 1946, which was subject to severe criticism from a young and yet unknown Roberto Levi-Castillo.

Despite having been a prolific researcher subject to numerous recognitions and honors, his salary never reflected his achievements and his life was marked by poverty. After the widespread introduction of DDT as a generic pesticide to control insect populations, he was convinced that his work on agricultural entomology was not relevant anymore. This led to a period of selfinflicted isolation and confinement within the walls of his museum collection, which at that time was housed at the Instituto Nacional de Higiene.

Campos-Rivadeneira passed away on May $5^{\text {th }}, 1962$. During his career, he described approximately 150 species of insects that were previously unknown to science. After his death, his beloved museum collection was neglected and eventually lost $(28,29)$. Ten years after his death, a group of biologists and scholars in Quito founded the Sociedad de Amigos de la Naturaleza Francisco Campos. This Society promoted the research and conservation of Ecuador's biodiversity and many relevant researchers at the time became members. In 1992, the Congress of Ecuador condecorated the Society for its contributions and also for helping to establish the Museo Ecuatoriano de Ciencias Naturales and the Fundación Natura (J. M. Carrión, personal communication).

\section{Roberto Levi-Castillo}

Levi-Castillo was born in Guayaquil on January $29^{\text {th }}, 1921$. Resembling Campos-Rivadeneira, Levi-Castillo's family was also part of a legacy of intellectuals and artists. His father was Roberto Levi Hoffman, who during the $19^{\text {th }}$ century attended his postgraduate studies under the guidance of Robert 
Koch and Paul Ehrlich. Levi Hoffman arrived in Ecuador in 1909 to work as the chief chemist for the Guayaquil laboratory and throughout the years became an influential person in many affairs related to the social, political, and commercial life of this city.

Levi-Castillo initiated his basic studies at a local school but was soon sent by his family to continue them in Europe. As a teenager, his father enrolled him at the Riverside Military Academy in Gainesville, GA, and he later moved to the Hollywood Military Academy in Pensacola, FL. He graduated in 1937 as a U.S. Army Air Force Reserve Second Lieutenant. He returned to Ecuador in 1938, and to obtain a locally recognized bachelor title, he completed an additional year of studies at the Colegio Nacional Vicente Rocafuerte. Soon after his return to Guayaquil, he was appointed as ad honorem instructor at the Escuela de Aviación Militar (38).

After finishing high school, he enrolled at the Universidad de Guayaquil and studied two simultaneous degrees: In chemistry and pharmaceutics and in medicine. With the start of the international tensions that led to World War II, he was called by the military to enroll as an army reserve officer. During the Ecuador-Perú war of 1941, he was garrisoned at a military base in the province of El Oro, where he took part in war actions. At some point during this armed conflict, he and two other cadets deserted and traveled to the Andean city of Cuenca. There, he had an emergency surgery due to a tooth infection which was further aggravated by a piece of gauze that was not removed. A severe infection required him to travel back to Guayaquil in sought of better medical treatment but was left with a cavity in his palate that required him to travel to the United States to receive proper treatment (38).

Perhaps taking advantage of his unplanned return to the United States, in 1942 he continued to study at Cornell Medical College. In 1943, he visited the Escuela de Medicina Tropical at the Universidad de La Habana in Cuba for an eight-month period. Once finished his training in Cuba, he returned to Cornell and received instruction as a US Army Special Forces Official under the leadership of Major William Barby (who was a decorated World War II war hero). That same year, he was assigned to missions in the allied countries and Italy. His tour of duty included Dundee (Scotland), North Africa, Sicily, Naples, and Anzio, where he helped to combat typhus fever outbreaks as a medical officer. Having an active role in the Sanitary Corps, he also went to Greece and Provence (France) to help control malaria outbreaks (38).

In 1944, he traveled to Fort Leavenworth, Kansas, to attend a Higher Command and Staff Course. Later that year, he returned to Guayaquil where he continued his studies at the Escuela de Química y Farmacia. He had an active role in many strikes against the Concejo Universitario to demand the upgrade of the School to the status of Faculty. During this time he also collaborated with Francisco Campos-Rivadeneira, with whom he took part in many excursions near Guayaquil city. As a result of this collaboration, he published several papers on the taxonomy of Anopheles (39-41). Then, in 1945, he set up the collaboration with the Public Health Inter-American Cooperative Service of the US government and moved to Quito where he worked as an epidemiologist and medical entomologist under Jaime Rivadeneira Dávila. During 1945, he published several important papers on the malaria vectors of the Ecuadorian Andean valleys $(42,43)$, a region where the disease was endemic at that time, but where it was later eradicated (44). In regards to his pioneering findings on the biology of Anopheles pseudopunctipennis, the primary vector species at the 
highlands of Ecuador at that time, he would remark, "My findings were widely discussed by foreign scientists, meanwhile, here in Ecuador people call me 'Doctor Mosquito' and make fun of me" (38).

Later, in 1946, he married a Dominican woman called Martina Bello Germán (38) and moved back to Guayaquil where he started his own research center at the now traditional "El Paraíso" neighborhood. His publications were greatly appreciated by the international scientific community due to the thoroughness of his analyses. He complemented his taxonomical and zoological descriptions with scientific illustrations and microphotographs taken with his camera, which he retrofitted to his microscope. He was fluent in Spanish, English, German, French, and Italian.

In 1947, he was appointed as a chemistry teacher at the Colegio Nacional Vicente Rocafuerte. This was a time during which he exchanged correspondence and maintained a healthy scientific controversy with the renowned Francisco Campos-Rivadeneira. His relationship with Campos-Rivadeneira was one of respect and cooperation. Moreover, Levi-Castillo acknowledged him as his mentor and a renowned entomologist (39). In 1949, he published two important scientific papers summarizing what was currently known at the time about South American malaria vectors, including his own original findings $(45,46)$, and also a preliminary list of Culex mosquito species from Ecuador (47). During the early 1950s, he published several papers on the mosquito fauna responsible for the transmission of yellow fever in Ecuador and South America (48-52). In December of 1951 , he received a doctorate title in Chemistry and Pharmaceutics. His thesis research was an analysis of the resistance of Culex quinquefasciatus to insecticides. He would later publish his results in a local journal (53).

In 1952, he was appointed as editor in chief of the Revista Ecuatoriana de Entomología y Parasitología. He also received the international "Carlos Finlay" medal, granted by the Sociedad Cubana de Medicina Tropical. The following ten years would be the most productive of his career, a time during which he traveled through the country collecting and cataloging the mosquito diversity of the Ecuadorian coast, the highlands, the Amazonian region, and the Galápagos Islands. The "Distribution of Haemagogus mosquitoes in Ecuador" (54), the description of several new species (55-64), and inventories of the Ecuadorian mosquito fauna are amongst some of its most influential papers $(6,47,65-66)$. Regarding other topics, he researched the possible use of the green algae Chara fragilis as a biological control for mosquito larvae $(67,68)$. Nevertheless, he did not find evidence of larvicidal properties. He designed a special box to transport live mosquito larvae and pupae collected from the field (69). He was also a pioneer in the use of male genitalia for the identification of mosquito species $(39,70)$ and was the first to use polyvinyl alcohol to prepare microscope slides of mosquito larvae, pupae, and male genitalia (71). Polyvinyl alcohol provides a superior medium that does not require the previous dehydration of specimens (72).

After divorcing his wife and getting remarried to Blanca Muñoz Aguirre, his promising scientific career ended abruptly in 1962. Disappointed by the lack of scientific interest in his young students and after a university strike that made him realize it would be nearly impossible to form new entomologists, he decided to retire from this field. This fateful decision can be understood and explained through this statement: "I understood that my way of thinking was ahead of the local culture and that entomology could not be the reason of my life any more in a society that doesn't have the economic resources to finance my diverse 
research interests. That is why I left science, sold all my equipment, burned down all my books, and abandoned the thing that brought me so much joy and illusion one day, to give way to other realities and, in search for them, I found in philately a new horizon. Immediately, I dedicated myself fervently to it and managed to gather various collections since I had a considerable fortune" (38).

Among his stamp collections, he held the "Scadta" and the "Panagra", which are some of the most valuable and rare stamp series of Ecuador. In 1960, he won the bronze medal at the Albert Hall International Exposition in London. In the long run, he became highly praised by international philatelic societies and recognized as the owner of the best and most complete collection of Ecuadorian stamps. Between 1959 and 1966, he wrote a weekly column at the "El Telégrafo" newspaper from Guayaquil where he would discuss various topics on philately (73).

In 1970, he made a leap into the study of history by collaborating with the historian Julio Estrada Icaza at the Archivo Histórico del Guayas. Soon afterward, his friend, the rear admiral Carlos Monteverde Granados, hired him to work at the Instituto de Historia Marítima and published several articles in the Institute's journal. In 1991, he became a member of the Asociación de Historiadores Ecuatorianos and in 1997, of the Academia Nacional de Historia.

Another important facet of his life was his involvement in Freemasonry, in which he was an active member at the Pythagoras Lodge in Washington, D.C., since 1946. He later enrolled at the Texas, Missouri, Kansas, New York, and lowa lodges. His association to Freemasonry in Ecuador was through the "Luz de América No. 5" Lodge. His essays on masonry were published at "Ars Quatuor Coronatorum" (London), which was an important research journal on the history of Freemasonry.

During the 1990s, he moved with his family to Ecuador's capital city, Quito, where he devoted himself to the investigation of historical subjects. He continued to write columns for national newspapers and the journal of the Universidad de Guayaquil. He passed away on October $29^{\text {th }}, 2006$, at the age of 85 . Versatile, self-taught, polyglot, and passionate, his production is scattered in different journals and newspapers of the world.

\section{Conclusions}

\section{The contributions of Campos-Rivadeneira and Levi-Castillo to the study of disease-transmitting mosquitoes in Ecuador}

During their prolific career, Campos-Rivadeneira and Levi-Castillo reported a total of 158 mosquito species for Ecuador, of which 12 were previously unknown in this country (supplementary material). Given the current estimate of approximately 252 mosquito species present in Ecuador $(12,15,17,20,21)$, both scientists described approximately $63 \%$ of the total mosquito fauna. Considering the rapid pace at which the study of mosquito diversity discovers new species, the contributions of contemporary and future researchers will slowly reduce the considerable bias towards what both Campos-Rivadeneira and Levi-Castillo did for entomology in Ecuador $(11,12,14,22)$. Nevertheless, both remain as the most prolific discoverers of mosquitoes in this country.

Campos-Rivadeneira reported a total of 32 mosquito species in Ecuador, 27 of these as new geographical records locally. Most of his specimens were collected in Guayaquil and its surroundings (Durán, Posorja, El Salado) or from nearby cities like Quevedo or Machala. He reported the presence of 
Aedes vexans in the Galápagos Islands. However, this was most likely a misidentification with the only native mosquito species that was known to be present in the archipelago at the time, Ae. taeniorhynchus (74). In 1954, Levi-Castillo claimed that Haemagogus equinus, previously reported by Campos-Rivadeneira (75), was not present in Ecuador and that most likely was misidentified with $\mathrm{Hg}$. panarchys or $\mathrm{Hg}$. spegazzini (76).

In 1918, Harrison G. Dyar described Ae. camposanus based on specimens from Guayaquil sent by Campos-Rivadeneira (77). However, in 1928, Dyar synonymized Ae. camposanus with Ae. euplocamus (78) only to be brought back from synonymy by Levi-Castillo $(79,80)$. More recently, Arnell synonymized it again as Ae. euplocamus (81) and nowadays it is a synonym of Ae. scapularis. In 1925, Dyar described Culex camposi, a new species, and named it after Campos-Rivadeneira (82). Nevertheless, Lane categorized it as a variety of $C x$. coronator (83) only to be recognized later again as a valid species by Bram (84). Throughout his career, Campos-Rivadeneira published at least 52 scientific papers dealing with different insect groups; further searches might reveal additional publications. However, we remain confident that we have included all of his publications dealing with mosquito taxonomy hereby.

Levi-Castillo reported a total of 136 species, of which 99 were new geographical records in Ecuador. His specimens were collected throughout all the Ecuadorian territory, from the highlands to the western and eastern lowlands. Yet, some of his collections require confirmation since for some specimens there is no specific reported locality and no other reference collections exist (Anopheles peryassui, $\mathrm{Hg}$. laecotaeniatus, Cx. originator, etc.). Levi-Castillo described 14 new mosquito species for science with specimens from Ecuador, these are An. gomezdelatorrei, Hg. soperi, Cx. babahoyensis, Cx. guayasi, Cx. quitensis, Limatus andinus, Li. guayasi, Trichoprosopon andinum, Tr. cotopaxense, Wyeomyia esmeraldasi, Wy. aequatoriana, Wy. amazonica, Toxorhynchites aequatorianus, and Uranotaeniaa equatorianna. Many of these have not been recorded again since their original description (2).

In 1959, Tx. aequatoriannus was listed as nomen dubium by Stone (85). While Stone does not give a reason for this change, it was most likely due to his lack of access to inspect type specimens. Tr. cotopaxense was originally described as Tr. cotopaxensis by Levi-Castillo and was later renamed by Stone (86); then, Zavortink categorized this species as nomen dubium advocating that its description seemed to include characteristics from at least three other species and most likely no type specimens exist (87). Other species described by Levi-Castillo were later synonymized by Stone (85); these are Ae. garciai (60) (synonym of Psorophora cingulata), Hg. garciai (88) (synonym of $\mathrm{Hg}$. boshelli), Cx. azuayus Levi-Castillo, 1954 (61) (synonym of Cx. nigripalpus) and Wy. aequatorialis Levi-Castillo, 1952 (55) (synonym of Wy. aphobema). Levi-Castillo also described two subspecies of $A n$. anopheles pseudopunctipennis: An. Ano. pseudopunctipennis ssp. levicastilloi (1944a) and An. Ano. pseudopunctipennis ssp. rivadeneirai (1945b) which to the present day are still recognized as valid (20).

Given Levi-Castillo's contributions to dipterology, in 1945, John Lane described $C x$. levicastilloi from specimens probably sent by Levi-Castillo from Ecuador (89). Interestingly, there is also a mosquito from Madagascar, Mymomyia (Ingramia) levicastilloi described by French entomologist Alexis Grjebine (1918-1988) in 1986 (90). Levi-Castillo probably met Grjebine in 1943 during his tour of duty around Europe (see section above). 
For the most part, and concurring with the report by Zavortink (87), mosquito specimens of Levi-Castillo that were kept at the Centro Ecuatoriano de Investigaciones Entomológicas (CIEI), in Guayaquil seem to have been lost. To our knowledge, the only existing collection by LeviCastillo seems to be the slides deposited at the U.S. National Entomology Collections (USNM) as reported by Zavortink (87), and some adult types deposited at this same museum (Cx. babahoyensis and Hg. soperi) (20). The whereabouts of the remaining specimens are currently unknown. It might be possible that his collection at the CIEI suffered a fate similar to that of his books when Levi-Castillo decided to abandon his entomological studies. Throughout his career, Levi-Castillo published a total of 65 papers, and we are confident that we have searched and included if not all, most of his production, particularly that dealing with mosquito taxonomy. Interestingly, both Campos-Rivadeneira and Levi-Castillo published their studies as single authors in the majority of their publications.

\section{A comment on the practice of science in Latin America during the first half of the $20^{\text {th }}$ century}

The reasons for the success or failure of both Campos-Rivadeneira and Levi-Castillo as scientists rely on a shared set of characteristics that appropriately represent the cultural and economic conditions that permeated most of the $20^{\text {th }}$ century in Ecuador and that affected how science and technology developed in this country.

Both Campos-Rivadeneira and Levi-Castillo lived at a time when the fate of Latin American countries was determined by an intense focus on the export of unprocessed materials and goods with little added value in knowledge and technology $(91,92)$. As a consequence, the majority of the population in Ecuador remained excluded from the development of new ideas, which reinforced their detachment from scientific inquiry and innovation and, thus, were not agents of societal change (93).

The lives and accomplishments as scientists of both Campos-Rivadeneira and Levi-Castillo share common ground in the fact that both were able to transcend the limitations of their time and society by privileged social and economic conditions. Their families belonged to a favorable combination of strong intellectual traditions, foreign higher education, and auspicious social connections. Even under such unique circumstances, both scientists performed under conditions defined by limited resources, low salaries, inadequate equipment, small libraries, isolation from scientific networks, and political instability (94), which have historically plagued the practice of science in Latin America.

The dependence on foreign education and cultural and professional connections to Europe and North America was also an essential component of the lives and professional careers of these Ecuadorian scientists. Without such foreign influence and support, it would have been nearly impossible for both to accomplish the productivity and notoriety for which they are now remembered at least within the narrow spectrum of Ecuadorian entomologists and historians. The exogenous influence in the contributions to science by Campos-Rivadeneira and Levi-Castillo was also related to how Latin American countries invested in science as an engine for rapid economic development. Contrary to the medical focus that characterized the research of these two scientists, very few success stories are known from Latin American scientists in theoretical and non-applied sciences (95). 
It has not been our intention to discuss the lives of these two scientists within a robust philosophical framework on the history of Latin American science, akin to the elaborate discussions in the field such as those of Saldaña (95). Nonetheless, we believe the lives of both Campos-Rivadeneira and Levi-Castillo could be considered as generalized paradigms that represent not only the political and social standards for the practice and development of science during the first half of the $20^{\text {th }}$ century in Ecuador, but also as figures that exemplify the overall conditions for the practice of science throughout most of the Latin American history. We could argue that, until recently, to be a successful scientist in Ecuador and most parts of Latin America, one needed to share similar conditions to the lives of both scientists discussed in this manuscript, including social and political connections enabling the support of government authorities to fund science activities directly connected to economic and productive concerns.

One should also regret the anticlimactic end of the scientific careers of both Campos-Rivadeneira and Levi-Castillo. Despite their sustained efforts to nurture and capitalize their individual scientific interests, they were never able to establish a self-sustained school of thought, through students and pupils who could have kept alive and improve on their contributions. This failure may have been related to the poor record of Ecuadorian higher education institutions, which for the most part of the $20^{\text {th }}$ century subsisted in a system which was 'impossible to explain, to evaluate, nor to defend on grounds of equity, efficiency, quality or its contribution to national development' (96).

The lives of Campos-Rivadeneira and Levi-Castillo are examples of fortitude and perseverance through difficult times, something that has characterized many Latin American scientists. It is through these difficulties and continuous struggle against the adversities of their culture and economies that it is possible to represent at least a particular aspect of the history of science in Latin America.

\section{Acknowledgments}

We want to extend our gratitude to our dear colleagues and true friends $D$. Donoso, A. Barragán, and M. Pinto, whose comments on earlier drafts helped to improve the quality of this manuscript. F. Salazar helped to obtain and digitize many of Campos-Rivadeneira's and Levi-Castillo's antique papers. J. M. Carrión kindly provided detailed information on the Sociedad de Amigos de la Naturaleza Francisco Campos.

We would also like to thank the editor and two anonymous reviewers whose suggestions contributed to improving the quality of our paper. The authors would like to dedicate this paper to Professor Giovanni Onore, eminent entomologist and mentor, who continues to inspire generations of Ecuadorian entomologists.

\section{References}

1. World Health Organization. A global brief on vector-borne diseases. Geneva: World Health Organization; 2014.

2. Leparc-Goffart I, Nougairede A, Cassadou S, Prat C, de Lamballerie X. Chikungunya in the Americas. Lancet. 2014;383:514. https://doi.org/10.1016/S0140-6736(14)60185-9

3. Fauci AS, Morens DM. Zika virus in the Americas - Yet another arbovirus threat. $\mathrm{N}$ Engl $\mathrm{J}$ Med. 2016;374:601-4. https://doi.org/10.1056/NEJMp1600297

4. Vasconcelos PFC, Calisher $\mathrm{CH}$. Emergence of human arboviral diseases in the Americas, 20002016. Vector-Borne Zoonotic Dis. 2016;16:295-301. https://doi.org/10.1089/vbz.2016.1952

5. Cao-Lormeau VM, Musso D. Emerging arboviruses in the Pacific. Lancet. 2014;384:1571-2. https://doi.org/10.1016/S0140-6736(14)61977-2 
6. Levi-Castillo R. Lista provisional y distribución de los mosquitos Culicinos del Ecuador. Revista Ecuatoriana de Entomología y Parasitología. 1953;1:34-45.

7. Campos FR. Estudios biológicos sobre los mosquitos de Guayaquil y alrededores. Revista del Colegio Nacional Vicente Rocafuerte. 1925;7:3-48.

8. Barragán AR, Dangles O, Cárdenas RE, Onore G. The History of Entomology in Ecuador. Annales de la Société entomologique de France. 2009;45:410-23.

9. Pinault LL, Hunter FF. Characterization of larval habitats of Anopheles albimanus, Anopheles pseudopunctipennis, Anopheles punctimacula, and Anopheles oswaldoi s.l. populations in lowland and highland Ecuador. J Vector Ecol. 2012;37:124-36. https://doi.org/10.1111/j.1948-7134.2012.00209.x

10. Pinault LL, Hunter FF. Larval habitat associations with human land uses, roads, rivers, and land cover for Anopheles albimanus, A. pseudopunctipennis, and A. punctimacula (Diptera: Culicidae) in Coastal and Highland Ecuador. Front Physiol. 2012;3:59. https://doi.org/10.3389/fphys.2012.00059

11. Pinault LL, Hunter FF. New highland distribution records of multiple Anopheles species in the Ecuadorian Andes. Malar J. 2011;10:236. https://doi.org/10.1186/1475-2875-10-236

12. Linton YM, Pecor JE, Porter CH, Mitchell LB, Garzón-Moreno A, Foley DH, et al. Mosquitoes of eastern Amazonian Ecuador: Biodiversity, bionomics and barcodes. Mem Inst Oswaldo Cruz. 2013;108(Suppl.1):100-9. https://doi.org/10.1590/0074-0276130440

13. Stewart-lbarra AM, Ryan SJ, Beltrán E, Mejía R, Silva M, Muñoz A. Dengue vector dynamics (Aedes aegypti) influenced by climate and social factors in Ecuador: Implications for targeted control. PLoS One. 2013;8:e78263. https://doi.org/10.1371/journal.pone.0078263

14. Navarro JC, Enríquez S, Vaca F, Benítez-Ortiz W. A new phytotelm plant, Crinum moorei (Asparagales: Amaryllidaceae), for the Americas and its mosquito inhabitant (Diptera: Culicidae) in Ecuador. Florida Entomol. 2013;96:1224-7.

15. Navarro JC, Duque PL, Liria J, Enríquez S, Vaca-Moyano F, Salazar JG. A new phytotelm plant for Ecuador Ananas comosus L. Merr. (Bromeliaceae) and its Wyeomyia species inhabitant (Diptera, Culicidae). CienciAmérica. 2018;7:1-15.

16. Navarro JC, Ponce P, Cevallos V. Dos nuevos registros de vectores potenciales de fiebre amarilla selvática y Mayaro para el Ecuador. Bol Malariol Salud Ambient. 2013;53:77-81.

17. Navarro JC, Enríquez S, Duque P, Campaña Y, Benítez-Ortiz W. New Sabethes (Diptera: Culicidae) species records for Ecuador, from Colonso-Chalupas biological reserve, province of Napo (Amazon). J Entomol Zool Stud. 2015;3:169-72.

18. Arregui G, Enríquez S, Benítez-Ortiz W, Navarro JC. Taxonomía molecular de Anopheles del Ecuador mediante ADN mitocondrial (Citocromo C Oxidasa I) y optimización por parsimonia máxima. Boletín Malariol Salud Ambient. 2015;55:128-36.

19. Navarro JC, Enríquez S, Duque P, Campaña WB. New mosquito species records for Ecuador, from Pululahua volcano (Andes) and Napo province (Amazon). J Entomol Zool Stud. 2015;3:392-6.

20. Clark JW, Linton Y-M, Pecor JE, Pecor D, Stoffer J, Motoki M, et al. Walter Reed Biosystematics Unit. Fecha de consulta: 16 de marzo de 2016. Disponible en: http://www.wrbu.org

21. Heinemann SJ, Belkin JN. Collection records of the project "Mosquitoes of Middle America". 13. South America: Brazil (BRA, BRAP, BRB), Ecuador (ECU), Perú (PER), Chile (CH). Mosq Syst. 1979;11:61-118.

22. Navarro JC, Enríquez S, Arrivillaga J, Benítez-Ortiz W. Un nuevo Aedes para la Amazonía de Ecuador y actualización taxonómica del género para el país. Boletín Malariol Salud Ambient. 2016;56:113-21.

23. Sierra R. Propuesta preliminar de un sistema de calsificación de vegetación para el ecuador continental. Quito: EcoCiencia; 1999. p. 194.

24. Hooghiemstra H, Wijninga VM, Cleef AM. The paleobotanical record of Colombia: Implications for biogeography and biodiversity. Ann Missouri Bot Gard. 2006;93:297-325.

25. Foster PG, Bergo ES, Bourke BP, Oliveira TMP, Nagaki SS, Sant'Ana DC, et al. Phylogenetic analysis and DNA-based species confirmation in Anopheles (Nyssorhynchus). PLoS One. 2013;8:e54063. https://doi.org/10.1371/journal.pone.0054063

26. Laurito M, Oliveira TM de, Almiron WR, Sallum MAM, Laurito M, de Oliveira TM, et al. COI barcode versus morphological identification of Culex (Culex) (Diptera: Culicidae) 
species: A case study using samples from Argentina and Brazil. Mem Inst Oswaldo Cruz. 2013;108:110-22. https://doi.org/10.1590/0074-0276130457

27. Reinert JF. List of abbreviations for currently valid generic-level taxa in family Culicidae (Diptera). Eur Mosq Bulletin. 2009;27:68-76.

28. Pérez-Pimentel R. Francisco Campos-Rivadeneira. Guayaquil: Archivo Biográfico Ecuador; 1994. p. 53-7.

29. Pino EA. Francisco Campos-Rivadeneira. Enciclopedia del Ecuador. Fecha de consulta: 28 de febrero de 2017. Disponible en: http://www.enciclopediadelecuador.com/personajeshistoricos/francisco-campos-rivadeneira/

30. Pérez-Pimentel R. Francisco Campos Coello. Guayaquil: Archivo Biográfico Ecuador; 1994. p. 74-7.

31. Escuela Politécnica Nacional. Luis Sodiro. Historia del Departamento de Biología de la EPN. 2016. Fecha de consulta: 30 de agosto de 2018. Disponible en: https://cienciasbiologicas. epn.edu.ec/index.php/galeria-home/historia

32. Ayala-Mora E. Historia de la revolución liberal ecuatoriana. Quito: Corporación Editora Nacional-Taller de Estudios Históricos; 1994.

33. Drake CJ, Chapman HC. New American water striders (Hemiptera). Florida Entomol. 1954;37:151-5.

34. Campos FR. Los Cicindelidae del Ecuador. Revista chilena de historia natural. 1921;25:448-52.

35. Campos FR. Estudios sobre la fauna entomológica del Ecuador. III, Coleópteros. Revista del Colegio Nacional Vicente Rocafuerte. 1921;6:26-106.

36. Campos FR. Estudios sobre la fauna entomologica del Ecuador. IX, Ortopteros. Revista del Colegio Nacional Vicente Rocafuerte. 1923;5:3-43.

37. Campos FR. Catálogo preliminar de los blátidos (cucarachas) del Ecuador. Revista del Colegio Nacional Vicente Rocafuerte. 1926;8:41-57.

38. Pérez-Pimentel R. Roberto-Leví Castillo. Guayaquil: Diccionario Biográfico de Ecuador; 1994. p. 189-93.

39. Levi-Castillo R. Clave para la identificación por los órganos masculinos (Terminalia) de los principales géneros, subgéneros y especies de anofelinos ecuatorianos. Quito: Imprenta de la Universidad de Guayaquil; 1944. p. 14

40. Levi-Castillo R. El complejo pseudopunctipennis en el Ecuador (Diptera, Culicidae). Guayaquil: Imprenta de la Universidad de Guayaquil; 1944. p.10.

41. Levi-Castillo R. Estudios sobre los Anofelinos de la región del Milagro. Revista de la Asociación de la Escuela de Ciencias Químicas. 1944;3:1-10.

42. Levi-Castillo R. Anopheles pseudopunctipennis in the Los Chillos Valley of Ecuador. J Econ Entomol. 1945;38:385-8.

43. Levi-Castillo R. A new variety of the Anopheles pseudopunctipennis complex in Ecuador (Diptera-Culicidae). Mosq News. 1945;5.

44. Pinault LL, Hunter FF. Malaria in highlands of Ecuador since 1900. Emerg Infect Dis. 2012;18:615-22. https://doi.org/1010.3201/eid1804.111267

45. Levi-Castillo R. The vectors of malaria on the Pacific slopes of South America, and their control. Rev Cubana Med Trop Parasitol. 1949;5:101-5.

46. Levi-Castillo R. Atlas de los anofelinos sudamericanos. Guayaquil: Imprenta de la Sociedad Filantrópica del Guayas; 1949. p. 206.

47. Levi-Castillo R. Lista provisional de los mosquitos Culex del Ecuador. Physis. 1949;20:190-3.

48. Levi-Castillo R. Estudio taxonómico sobre los principales vectores de la fiebre amarilla selvática en América del Sur. I. Terminalias masculinas de los mosquitos Haemagogus. Rev Cubana Med Trop Parasitol. 1951;7:13-6.

49. Levi-Castillo R. Notas sobre la dispersión del género "Haemagogus" en América del Sur y su importancia en la epidemiologia de la fiebre amarilla selvática. Revista de Sanidad e Higiene Pública. 1951;25:213-21.

50. Levi-Castillo R. Los mosquitos del género Haemagogus-Williston, 1896 en América del Sur. Cuenca: Editorial "Don Bosco"; 1951. p. 77. 
51. Levi-Castillo R. Epidemiologic studies on jungle yellow fever in the provinces of Manabi and Esmeraldas of the coastal zone of the Republic of Ecuador. Rev Cubana Med Trop Parasitol. 1952;8:76-81.

52. Levi-Castillo R. The epidemiology of jungle yellow fever in coastal regions of Ecuador. $Z$ Tropenmed Parasitol. 1953;4:254-65.

53. Levi-Castillo R. The appearance of resistance to residual insecticides in Culex pipiens quinquefasciatus (fatigans) in the city of Guayaquil. Revista Ecuatoriana de Entomología y Parasitología. 1953;1:7-16.

54. Levi-Castillo R. Distribution of Haemagogus Mosquitoes in Ecuador. Revista Ecuatoriana de Entomología y Parasitología. 1954;2:410-6.

55. Levi-Castillo R. Wyemoyia (Wyeomyia) aphobema var. aequatorialis var. n., a new sabethine mosquito from Ecuador (Diptera: Culicidae). Proc R Entomol Soc London. 1952;21:130-3.

56. Levi-Castillo R. Una nueva especie de Culex procedente de la Provincia de Los Ríos, Ecuador: Culex (Carrollia) babahoyensis N. Sp. (Diptera-Culicidae). Revista Ecuatoriana de Entomología y Parasitología. 1953;1:91-4.

57. Levi-Castillo R. Toxohrynchites aequatorianus n. sp., especie nueva de Toxorhynchites hallada en Pichilingue, Los Ríos, Ecuador (Diptera-Culicidae). Revista Ecuatoriana de Entomología y Parasitología. 1953;1:71-9.

58. Levi-Castillo R. Dos especies nuevas de mosquitos ecuatorianos. Revista Ecuatoriana de Entomología y Parasitología. 1953;1:14-8.

59. Levi-Castillo R. Dos especies nuevas de mosquitos de la sierra ecuatoriana (DipteraCulicidae). Revista Ecuatoriana de Entomología y Parasitología. 1953;1:63-70.

60. Levi-Castillo R.Aedes garciai n. sp., un aedino nuevo para la fauna ecuatoriana. Lanesia, nuevo subgénero de Aedes. Revista Ecuatoriana de Entomología y Parasitología. 1953;1:101-9.

61. Levi-Castillo R. Culex (Phalangomyia) azuayus n. sp., un nuevo mosquito de altura del Ecuador. Revista Ecuatoriana de Entomología y Parasitología. 1954;2:263-71.

62. Levi-Castillo R. Cuatro especies nuevas de Sabethini del Ecuador (Diptera--Culicidae). Revista Ecuatoriana de Entomología y Parasitología. 1954;2:247-60.

63. Levi-Castillo R. Phoniomyia esmeraldasi, a new mosquito from Ecuador. Revista Ecuatoriana de Entomología y Parasitología. 1955;2:389-92.

64. Levi-Castillo R. Un nuevo anofelino de altura del Ecuador: Anopheles gomezdelatorrei n. sp. Revista Ecuatoriana de Entomología y Parasitología. 1955;2:509-16.

65. Levi-Castillo R. Notas sobre la fauna culicidiana de las Provincias de Azuay y Cañar en la Región Austral del Ecuador (Diptera-Culicidae). Revista Ecuatoriana de Entomología y Parasitología. 1954;2:39-50.

66. Levi-Castillo R. Catálogo de los anofelinos de la República del Ecuador. Guayaquil: Artes Gráficas Senefelder C.A.; 1945. p.172.

67. Levi-Castillo R. The possible role of Chara fragilis in mosquito control. Science. 1944;100:266. https://doi.org/10.1126/science.100.2595.266

68. Levi-Castillo R. Experiments on control of mosquitos by means of Characeae. Boletín del Instituto Botánico de la Universidad Central del Ecuador. 1945;5:123-8.

69. Levi-Castillo R. Una caja para transportar larvas de mosquito vivas. Rev Cubana Med Trop Parasitol. 1947;3:211-2.

70. Levi-Castillo R. Key for the Identification by means of the male genitalia of the principal genera, subgenera and species of Anophelines of Ecuador. Revista Médica de Córdoba. 1944;8:14.

71. Levi-Castillo R. El uso del alcohol polivinílico de viscosidad media como un medio para el montaje de las larvas, pupas y terminalia masculina de los mosquitos. Rev Cubana Med Trop Parasitol. 1950;6:76-8.

72. MetcaLfe CR, Richardson FR. The use of polyvinyl alcohol and related compoumds as a mounting medium for microscope slides. Kew Bull. 1949;4:569-71.

73. Anónimo. Dr. Roberto Levi-Castillo: Diario El Telégrafo. In Guayaquil, Ecuador: Club Filatélico Guayaquil; 2018. Fecha de consulta: 8 de marzo de 2018. Disponible en: http:// www.guayaquilfilatelico.org/biblioteca.php 
74. Bataille A, Cunningham AA, Cedeño V, Patiño L, Constantinou A, Kramer LD, et al. Natural colonization and adaptation of a mosquito species in Galápagos and its implications for disease threats to endemic wildlife. Proc Natl Acad Sci USA. 2009;106:10230-5. https://doi.org/10.1073/pnas.0901308106

75. Campos FR. Estudios sobre la fauna entomológica del Ecuador. $2^{\circ}$ Dipteros Nematóceros: Fam. Culicidae (Mosquitos). Revista del Colegio Nacional Vicente Rocafuerte. 1922;18-30

76. Levi-Castillo R. Notes on Ecuadorian mosquitoes- Haemagogus equinus in Ecuador and further taxonomic notes on Uranotaenia Levi-Castillo 1953. Revista Ecuatoriana de Entomología y Parasitología. 1954;2:83-8.

77. Dyar HG. New American mosquitoes. Insecutor Inscitiae Menstruus. 1918;6:120-9.

78. Dyar HG. The mosquitoes of the Americas. Washington, D.C.: Carnegie Institution of Washington; 1928.

79. Levi-Castillo R. Nota taxonómica sobre la especie ecuatoriana Aedes (Ochlerotatus) camposanus Dyar 1918 (Dipt. Culicidae). Rev Entomol. 1951;22:383-8.

80. Levi-Castillo R. Redescription of Aedes (Ochlerotatus) camposanus Dyar (1918) as a valid species found in the Coastal Plain of Ecuador. Pacific Science. 1952;VI:262-4.

81. Arnell JH. Mosquito studies (Diptera, Culicidae) XXXIII. A revision of the Scapularis Group of Aedes (Ochlerotatus). Contrib Am Entomol Inst. 1976;13:1-144.

82. Dyar HG. Some mosquitoes from Ecuador (Diptera, Culicidae). Insecutor Inscitiae Menstruus. 1925;13:27-31.

83. Lane J. Neotropical Culicidae - Volume I - Dixinae, Chaoborinae and Culicinae, tribes Anophelini, Toxorhychitini and Culicini (Genus Culex only). Vol. I. São Paulo: University of São Paulo; 1953. p. 550.

84. Bram R. Clasificación de los mosquitos Culex del subgénero Culex (Diptera: Culicidae) en el Nuevo Mundo. Proceedings of the United States Natural Museum. 1967;120:1-122.

85. Stone A, Knight KL, Starcke H. A synoptic catalog of the mosquitoes of the world (Diptera, Culicidae). Washington, D.C.: Entomological Society of America, Thomas Say Foundation; 1959. p. 358.

86. Stone A. A synoptic catalog of the mosquitoes of the world, supplement III. (Diptera: Culicidae). Catálogo sinóptico de los zancudos del mundo, suplemento IV (Diptera: Culicidae). Proceedings of the Entomological Society of Washington. 1967;69:197-224.

87. Zavortink T. The new sabethine genus Johnbelkinia and a preliminary reclassification of the composite genus Trichoprosopon. Contrib Am Entomol Inst. 1979;17:p. 1-61.

88. Levi-Castillo R. Nueva división sistemática del género Haemagogus Williston 1896 y una nueva especie ecuatoriana: Haemagogus garciai, n. sp. Revista Ecuatoriana de Entomología y Parasitología. 1955;2:359-66.

89. Lane J. Quatro especies novas de Culex da Regiao Neotropical. Rev Entomol Rio Janeiro. 1945;16:204-9.

90. Grjebine A. Insectes Diptères Culicidae Culicinae Ficalbiini. Vol. 68, Faune de Madagascar. Paris: Muséum Nationale d'Histoire Naturelle; 1986. p. 441.

91. Bértola L, Ocampo JA. Latin America. In: Baten J. A history of the global economy 1500 to the present. Cambridge, UK: Cambridge University Press; 2015. p. 121-57.

92. Vega-Jurado J, Fernández-de-Lucio I, Huanca R. University-industry relations in Bolivia: Implications for university transformations in Latin America. High Education. 2008;56:205-20.

93. Arocena R, Sutz J. Latin American universities: from an original revolution to an uncertain transition. High Education. 2005;50:573-92.

94. Canizares-Esguerra J, Cueto M. Latin American Science: The Long View. NACLA Rep Am. 2016;35:265-581.

95. Saldaña JJ. Science in Latin America: A history. Austin: The University of Texas Press; 2006.

96. Jameson K. Higher education in a vacuum: Stress and reform in Ecuador. High Education. 1997;33:265-81. 


\section{Supplementary material}

List of mosquito species collected, described, and reported by F. Campos-Rivadeneira and R. Levi-Castillo for Ecuador. For each species, the collection localities reported on their publications are listed.

Subfamily Anophelinae

Genus Anopheles Meigen, 1818

Subgenus Anopheles Meigen, 1818

1. Anopheles (Anopheles) apicimacula Dyar \& Knab, 1906. Guayas, El Oro, Los Ríos, Manabí, and Esmeraldas (1). No specific locality data (2).

2. Anopheles (Anopheles) eiseni Coquillett, 1902. Esmeraldas, Manabí, Guayas, Los Ríos, El Oro, Chimborazo, Pichincha, Azuay, Cañar, Loja, Cotopaxi, Imbabura, and Carchi. Up to 2000 m (1). No specific locality data (2).

3. Anopheles (Anopheles) mediopunctatus Lutz, 1903. Guayas: Guayaquil and its surroundings (3). Esmeraldas, Los Ríos, Manabí, and Guayas (1). No specific locality data (Levi-Castillo 1958).

4. Anopheles (Anopheles) neomaculipalpus Curry, 1931. Cañar, Azuay, and Loja (2).

5. Anopheles (Anopheles) peryassui Dyar \& Knab, 1908. No specific locality data (2).

6. Anopheles (Anopheles) pseudopunctipennis Theobald, 1901. Guayas: Guayaquil and its surroundings (3). Guayas: Milagro (4). From sea level up to 2500 m (1).

7. Anopheles (Anopheles) pseudopunctipennis ssp. Levicastilloi Levi-Castillo 1944. Type locality: Ecuador, Guayas, from Bucay to Progreso (5). Guayas: Bucay (1). Coastal lowland regions up to 300 MASL; provinces of Esmeraldas, Manabí, Los Ríos, Guayas, and El Oro (1). No specific locality data (5).

8. Anopheles (Anopheles) pseudopunctipennis ssp. rivadeneirai Levi-Castillo 1945. Type locality: Ecuador, InterAndean region valleys up to $2500 \mathrm{MASL}$, provinces of Carchi, Imbabura, Pichincha, Cotopaxi, Tungurahua, Chimborazo, Cafiar, Azuay, and Loja (1). Pichincha: Los Chillos Valley (6). No specific locality data (2).

9. Anopheles (Anopheles) punctimacula Dyar \& Knab, 1906. Guayas: Guayaquil and its surroundings, Chobo, Barraganetal, San Rafael (3,7). Guayas: Guayaquil (8). Guayas: Milagro (4). El Oro, Los Ríos, Esmeraldas, Manabí, Guayas, up to 280 m (1).

10. Anopheles (Anopheles) shannoni Davis, 1931. No specific locality data (2).

Subgenus Kerteszia Theobald, 1905

11. Anopheles (Kerteszia) boliviensis (Theobald, 1905). Napo (formerly Napo-Pastaza), Morona-Santiago (formerly Santiago-Zamora) (1).

12. Anopheles (Kerteszia) homunculus Komp, 1937. No specific locality data (2).

13. Anopheles (Kerteszia) neivai Howard, Dyar \& Knab, 1913. Guayas: Guayaquil, Posorja (3,7). Esmeraldas, Manabí, Guayas, El Oro, Los Ríos (1).

Subgenus Lophopodomyia Antunes, 1937

14. Anopheles (Lophopodomyia) gomezdelatorrei Levi-Castillo, 1955. Type locality: Ecuador, Carchi, Chiltazon, altitude $2,880 \mathrm{~m}$, cave $(2,9)$.

15. Anopheles (Lophopodomyia) squamifemur Antunes, 1937. No specific locality data (2).

16. Anopheles (Lophopodomyia) vargasi. Gabaldón, Cova García \& López, 1941. No specific locality data (2).

Subgenus Nyssorhynchus Blanchard, 1902 
17. Anopheles (Nyssorhynchus) albimanus Wiedemann, 1820. Guayas: Guayaquil (8). Guayas: Guayaquil, Durán, San Rafael, Posorja (3). Guayas: Milagro (4). Guayas, El Oro, Manabí, Los Ríos, Esmeraldas (1). No specific locality data (2).

18. Anopheles (Nyssorhynchus) aquasalis Curry, 1932. Esmeraldas, Guayas, Manabí, Santa Elena: Palmar, El Oro (1).

19. Anopheles (Nyssorhynchus) argyritarsis Robineau-Desvoidy, 1827. No specific locality data (2).

20. Anopheles (Nyssorhynchus) darlingi Root, 1926. No specific locality data (2).

21. Anopheles (Nyssorhynchus) oswaldoi (Peryassú, 1922). No specific locality data (2).

22. Anopheles (Nyssorhynchus) rangeli Gabaldón, Cova García \& López, 1940. No specific locality data (2).

23. Anopheles (Nyssorhynchus) strodei Root, 1926. No specific locality data (2).

Subgenus Stethomyia Theobald, 1902

24. Anopheles (Stethomyia) acanthotorynus Komp, 1937. No specific locality data (2).

25. Anopheles (Stethomyia) kompi Edwards, 1930. No specific locality data $(2,10)$.

Genus Chagasia Cruz, 1906

26. Chagasia bathana (Dyar, 1928). Guayas: Road to Salinas, Manabí (1). No specific locality data (2).

Subfamily Culicinae

Genus Aedeomyia Theobald, 1901

Subenus Aedeomyia Theobald, 1901

27. Aedeomyia (Aedomyia) squamipennis (Lynch Arribálzaga, 1878). Guayas: Guayaquil and its surroundings (3). Guayas: Guayaquil, Yaguachi, Milagro, Salitre (11). Guayas, Los Ríos, El Oro (12).

Genus Aedes sensu Meigen, 1818

Subgenus Georgecraigius Reinert, Harbach \& Kitching, 2006

28. Aedes (Georgecraigius) fluviatilis (Lutz, 1904). Napo (formerly Napo-Pastaza): Tena; Pastaza (formerly NapoPastaza): Arajuno, Shell-Mera (11). No specific locality data (2).

Subgenus Howardina Theobald, 1903

29. Aedes (Howardina) albonotatus (Coquillett, 1906). Santo Domingo de los Tsáchilas (formerly part of Esmeraldas): Santo Domingo de los Colorados; Esmeraldas: Quinindé (11). Pichincha, Imbabura, Bolivar and Chimborazo (10). No specific locality data (2).

30. Aedes (Howardina) pseudodominicii Komp, 1936. Napo (formerly Napo-Pastaza): lla, Napo, Tena (11). Napo (formerly Napo-Pastaza) (10).

31. Aedes (Howardina) quadrivittatus (Coquillett, 1902). Azuay, Cañar, Pichincha, and Imbabura (10). No specific locality data (2).

32. Aedes (Howardina) sexlineatus (Theobald, 1901). Napo (formerly Napo-Pastaza): Tena; Pastaza (formerly Napo-Pastaza): Arajuno (11).

Subgenus Ochlerotatus Lynch Arribálzaga, 1891

33. Aedes (Ochlerotatus) angustivittatus Dyar \& Knab, 1907. Napo (formerly Napo-Pastaza): Tena, Ila, Napo; 
Pastaza (formerly Napo-Pastaza): Puyo (11). Napo (formerly Napo-Pastaza) (10). No specific locality data (2).

34. Aedes (Ochlerotatus) euplocamus Dyar \& Knab, 1906. Guayas: Milagro (4).

35. Aedes (Ochlerotatus) fulvus (Wiedemann, 1828). Guayaquil and its surroundings $(3,7)$.

36. Aedes (Ochlerotatus) milleri Dyar, 1922. Cañar, Loja, Chimborazo, Cotopaxi, Pichincha, Imbabura, Azuay: Cuenca, Río Tomebamba, 2600 m (13); Monay, Paute, Girón, Azogues, and Biblián (14). No specific locality data (2).

37. Aedes (Ochlerotatus) scapularis (Rondani, 1848). Guayas: Guayaquil, El Salado, Durán (3,7). Guayas: Guayaquil (8). Guayas: Mlilagro (4). Guayas: Guayaquil, Chongón, Puná, Yaguachi, Milagro; Napo (formerly Napo-Pastaza): Tena, Ila, Napo (11). Guayas, El Oro, Los Ríos, Napo (formerly Napo-Pastaza) (10). No specific locality data (2).

38. Aedes (Ochlerotatus) serratus (Theobald, 1901). Santo Domingo de los Tsáchilas (formerly part of Esmeraldas): Santo Domingo de los Colorados; Esmeraldas: Quinindé, Viche (11). Guayas, Manabí, Esmeraldas, Pichincha, Los Ríos, and Napo (formerly Napo-Pastaza) (10). No specific locality data (2).

39. Aedes (Ochlerotatus) taeniorhynchus (Wiedemann, 1821). Guayas: Guayaquil, Durán, Posorja (3,7). Guayas: Milagro (4). Guayas: Guayaquil, Yaguachi, Milagro, Puná (11). Guayas, Manabí, Esmeraldas, El Oro, Galápagos (10). No specific locality data (2).

Subgenus Protomacleaya Theobald, 1907

40. Aedes (Protomacleaya) metoecopus Dyar, 1925. Guayas: Guayaquil and its surroundings (3). Guayas, Manabí, Los Ríos (10). No specific locality data (2).

41. Aedes (Protomacleaya) terrens (Walker, 1856).Guayas: Guayaquil, Yaguachi, Milagro, Pascuales, Chongón, Progreso; Manabí: Chone, Calceta, Santa Ana; Esmeraldas: Quinindé (11).

Genus Coquillettidia Dyar, 1905

Subgenus Rynchotaenia Brethés, 1910

42. Coquillettidia (Rhynchotaenia) nigricans (Coquillett, 1904). Los Ríos(10). No specific locality data (2).

Genus Culex Linnaeus, 1758

Subgenus Aedinus Lutz, 1904

43. Culex (Aedinus) amazonensis (Lutz, 1905). No specific locality data (2).

Subgenus Anoediporpa Dyar, 1923

44. Culex (Anoedioporpa) conservator Dyar \& Knab, 1906. No specific locality data (2).

45. Culex (Anoedioporpa) originator Gordon \& Evans, 1922. No specific locality data (2).

Subgenus Carrollia Lutz, 1905

46. Culex (Carrollia) babahoyensis Levi-Castillo, 1953. Type locality: Ecuador, Los Ríos: Juan Montalvo, Hacienda "Mora" (15,16). Los Ríos (10). No specific locality data (2).

47. Culex (Carrollia) bihaicola Dyar \& Nuñez Tovar, 1927. Santo Domingo de los Tsáchilas: Santo Domingo de los Colorados (formerly part of Esmeraldas); Esmeraldas: Quinindé (11). Guayas, Manabí, Esmeraldas, and Pichincha (10).

48. Culex (Carrollia) infoliatus Bonne-Wepster \& Bonne, 1920. Napo (formerly Napo-Pastaza): Tena, lla, Napo; Pastaza (formerly Napo-Pastaza): Puyo, Shell-Mera, Mera (11). Napo (formerly Napo-Pastaza), MoronaSantiago (formerly Santiago-Zamora) $(10,17)$. No specific locality data (2). 
49. Culex (Carrollia) iridescens Lutz, 1905. Napo (formerly Napo-Pastaza), Morona-Santiago (formerly SantiagoZamora) (17). Napo (formerly Napo-Pastaza): Tena, Ila, Napo, Canelos; Pastaza (formerly Napo-Pastaza): Puyo, Canelos (11). No specific locality data (2).

50. Culex (Carrollia) metempsytus Dyar, 1921. Napo (formerly Napo-Pastaza): Tena; Pastaza (formerly NapoPastaza): Arajuno, Shell-Mera (11). Napo (formerly Napo-Pastaza), Morona-Santiago (formerly SantiagoZamora) $(10,17)$.

51. Culex (Carrollia) secundus Bonne-Wepster \& Bonne, 1920. Pastaza (formerly Napo-Pastaza): Tena, Arajuno, Shell-Mera (11). Napo (formerly Napo-Pastaza), Morona-Santiago (formerly Santiago-Zamora) $(10,17)$. No specific locality data (2).

52. Culex (Carrollia) urichii (Coquillett, 1906). Napo (formerly Napo-Pastaza): Tena; Pastaza (formerly NapoPastaza): Arajuno (11). Napo (formerly Napo-Pastaza), Morona-Santiago (formerly Santiago-Zamora) $(10,17)$. No specific locality data (2).

Subgenus Culex Linnaeus, 1758

53. Culex (Culex) archegus Dyar, 1929. Azuay: Cuenca, Monay (11). Azuay: Cuenca $(18,19)$.

54. Culex (Culex) articularis Philippi, 1865. Azuay, Cañar, Chimborazo y Loja (10). No specific locality data (2).

55. Culex (Culex) camposi Dyar, 1925. Synonym: Culex coronatorcamposi, resurrected from syn coronator Bram, 1967. Guayas: Guayaquil, Chongón, Yaguachi, Milagro; Los Ríos: Baba, Vinces, Babahoyo, Mocache, Palenque, Quevedo; El Oro: Machala, Puerto Bolívar, Santa Rosa, La Emerenciana, Piñas, Portovelo (11). Guayas, El Oro, Los Ríos (10,17). No specific locality data (2).

56. Culex (Culex) chidesteri Dyar, 1921 Napo: Tena, Ila (11). Napo, Orellana, Pastaza (formerly Napo-Pastaza), Morona-Santiago and Zamora-Chinchipe $(10,17)$.

57. Culex (Culex) coronator Dyar \& Knab, 1906. Guayas: Guayaquil, Durán (3,7). Napo (formerly Napo-Pastaza): Tena, Ila, Napo; Pastaza (formerly Napo-Pastaza): Puyo (11). Napo (formerly Napo-Pastaza), MoronaSantiago (formerly Santiago-Zamora) $(10,17)$. No specific locality data (2).

58. Culex (Culex) guayasi Levi-Castillo, 1953. Type locality: Ecuador, Babahoyo, Los Ríos(10,20). Los Ríos (10). No specific locality data (2).

59. Culex (Culex) levicastilloi Lane, 1945. El Oro: Machala, Santa Rosa, La Emerenciana, Puerto Bolívar(11).El Oro (10). No specific locality data (2).

60. Culex (Culex) maracayensis Evans, 1923. No specific locality data (2).

61. Culex (Culex) mollis Dyar \& Knab, 1906. Guayas: Guayaquil, Tenguel; El Oro: Machala, Puerto Bolívar; Los Ríos: Babahoyo, Vinces, Palenque; Esmeraldas: Esmeraldas, Táchina, Limones; Manabí: Jipijapa, Chone, Santa Ana, Calceta; Napo (formerly Napo-Pastaza): Ila, Napo, Tena (11). Guayas, El Oro, Los Ríos, Manabí, Esmeraldas, Napo (formerly Napo-Pastaza) and Morona-Santiago (formerly Santiago-Zamora) $(10,17)$. No specific locality data (2).

62. Culex (Culex) nigripalpus Theobald, 1901. Guayas: Guayaquil and its surroundings (3,7). Guayas: Milagro (4). Guayas: Guayaquil, Yaguachi, Milagro, Venecia, Pascuales, Tenguel, Puná, Chongón, Progreso, Balzar; El Oro: Machala, Puerto Bolívar, Pasaje; Manabí: Portoviejo, Manta; Esmeraldas: Táchina, Quinindé; Los Ríos: Vinces, Mocache, Palenque, Quevedo, Baba, Babahoyo; Napo (formerly Napo-Pastaza): Tena; Pastaza (formerly Napo-Pastaza): Shell-Mera (11). Guayas, El Oro, Manabí, Los Ríos, Esmeraldas, Napo (formerly Napo-Pastaza), and Morona-Santiago (formerly Santiago-Zamora) (10,17). Azuay: Zhurucuchu and Llullucchas regions (21). No specific locality data (2).

63. Culex (Culex) quinquefasciatus Say, 1823. Guayas: Guayas: Guayas: Guayaquil, Durán. Naranjal $(3,7)$. Guayas: Milagro (4). Bolívar (formerly part of Los Ríos): Balsapamba; Guayas: Guayaquil, Chongón, Yaguachi, Milagro, Venecia, Naranjito, Bucay, Progreso, General Villamil, Pascuales, La Toma, Manglaralto, Tenguel, 
Puná, Balzar, Daule; Los Ríos: Babahoyo, Baba, Vinces, Jujan, Mocache, Palenque, Quevedo, La Angélica, Barreiro, Montalvo, Playas de Vinces; Esmeraldas: Esmeraldas, Táchina, Quinindé, Río Verde, Limones; El Oro: Machala, Puerto Bolívar, La Emerenciana, Bellavista, Santa Rosa, El Guabo, Pasaje; Manabí: Portoviejo, Manta, Bahía, Junín, Chone, Calceta, Santa Ana, Jipijapa, Puerto Cayo, Machalilla, San Vicente (11). Guayas, El Oro, Los Ríos, Manabí, Esmeraldas, Islas Galápagos, Napo (formerly Napo-Pastaza), and Morona-Santiago (formerly Santiago-Zamora) $(10,17)$. Guayas: Guayaquil (22). No specific locality data (2).

64. Culex (Culex) quitensis Levi-Castillo, 1953. Type locality: Ecuador, Pichincha, Quito (18). Cotopaxi, Pichincha, and Imbabura (10). No specific locality data (2).

65. Culex (Culex) usquatissimus Dyar, 1922. Guayas: Guayaquil and its surroundings (3).

Subgenus Melanoconion Theobald, 1903

66. Culex (Melanoconion) albinensis Bonne-Wepster \& Bonne, 1920. No specific locality data (2).

67. Culex (Melanoconion) bastagarius Dyar \& Knab, 1906. Napo (formerly Napo-Pastaza): Tena, Napo; Pastaza (formerly Napo-Pastaza): Puyo (11). Los Ríos, Guayas, Napo (formerly Napo-Pastaza) (10). Morona-Santiago (formerly Santiago-Zamora) (17). No specific locality data (2).

68. Culex (Melanoconion) comatus Senevet \& Abonnenc, 1939. No specific locality data (2).

69. Culex (Melanoconion) conspirator Dyar \& Knab, 1906. Guayas: Guayaquil and its surroundings (3). Guayas, Los Ríos, Manabí, Esmeraldas, and El Oro (17). No specific locality data (2).

70. Culex (Melanoconion) distinguendus Dyar, 1928. Napo (formerly Napo-Pastaza): Tena (11). Napo (formerly Napo-Pastaza), Morona-Santiago (formerly Santiago-Zamora) (10,17). No specific locality data (2).

71. Culex (Melanoconion) dunni Dyar, 1918. Napo (formerly Napo-Pastaza): Tena, Napo, Ila (11). Los Ríos, Napo (formerly Napo-Pastaza), Morona-Santiago (formerly Santiago-Zamora) $(10,17)$. No specific locality data (2).

72. Culex (Melanoconion) eastor Dyar, 1920. Pastaza (formerly Napo-Pastaza): Arajuno (11). Napo (formerly Napo-Pastaza), Morona-Santiago (formerly Santiago-Zamora) $(10,17)$. No specific locality data (2).

73. Culex (Melanoconion) educator Dyar \& Knab, 1906. Pastaza (formerly Napo-Pastaza): Mera, Shell-Mera, Puyo (11). Napo (formerly Napo-Pastaza), Morona-Santiago (formerly Santiago-Zamora) (10,17). No specific locality data (2).

74. Culex (Melanoconion) elevator Dyar \& Knab, 1906. Napo (formerly Napo-Pastaza): Tena; Pastaza (formerly Napo-Pastaza): Puyo (11). Napo (formerly Napo-Pastaza), Morona-Santiago (formerly Santiago-Zamora) $(10,17)$. No specific locality data (2).

75. Culex (Melanoconion) erraticus (Dyar \& Knab, 1906). Los Ríos (10). No specific locality data (2).

76. Culex (Melanoconion) innovator Evans, 1924. No specific locality data (2).

77. Culex (Melanoconion) inhibitator Dyar \& Knab, 1906. Napo (formerly Napo-Pastaza): Tena, Ila, Napo (11). Napo (formerly Napo-Pastaza), Morona-Santiago (formerly Santiago-Zamora) (10,17). No specific locality data (2).

78. Culex (Melanoconion) iolambdis Dyar, 1918. No specific locality data (2).

79. Culex (Melanoconion) madininensis Senevert, 1936. No specific locality data (2).

80. Culex (Melanoconion) phlogistus Dyar, 1920. Los Ríos(10). No specific locality data (2).

81. Culex (Melanoconion) pilosus Lee, 1946. Guayas: Guayaquil and its surroundings (3,7). Guayas, Guayas: Guayaquil, Yaguachi, Milagro, Pascuales; Los Ríos: Baba, Babahoyo, Vinces, Mocache; El Oro: Machala, Santa Rosa, Pasaje, La Emerenciana, Bellavista; Esmeraldas: Esmeraldas, Limones, Río Verde, Táchina; Napo (formerly Napo-Pastaza):Ila, Napo, Tena; Pastaza (formerly Napo-Pastaza): Arajuno (11). Guayas, El Oro, Los Ríos, Manabí, Esmeraldas, Napo (formerly Napo-Pastaza) and Morona-Santiago (formerly SantiagoZamora) (10,17). No specific locality data (2). 
82. Culex (Melanoconion) plectoporpe Root, 1927. No specific locality data (2).

83. Culex (Melanoconion) putumayensis Matheson, 1934. Pastaza (formerly Napo-Pastaza): Arajuno (11). Napo (formerly Napo-Pastaza), Morona-Santiago (formerly Santiago-Zamora) (10,17). No specific locality data (2).

84. Culex (Melanoconion) saramaccensis Bonne-Wepster \& Bonne, 1920. Napo (formerly Napo-Pastaza), Morona-Santiago (formerly Santiago-Zamora) (17).

85. Culex (Melanoconion) spissipes (Theobald, 1903). No specific locality data (2).

86. Culex (Melanoconion) taeniopus Dyar \& Knab, 1907. Napo (formerly Napo-Pastaza): Tena; Pastaza (formerly Napo-Pastaza): Puyo (11). Napo (formerly Napo-Pastaza), Morona-Santiago (formerly Santiago-Zamora) $(10,17)$. No specific locality data (2).

87. Culex (Melanoconion) theobaldi (Lutz, 1904). Los Ríos, Napo (formerly Napo-Pastaza) (10). No specific locality data (2).

Subgenus Microculex Theobald, 1907

88. Culex (Microculex) chryselatus Dyar \& Knab, 1919. Napo (formerly Napo-Pastaza): Tena; Pastaza: Arajuno (11). Napo, (formerly Napo-Pastaza), Morona-Santiago (formerly Santiago-Zamora) $(10,17)$. No specific locality data (2).

89. Culex (Microculex) imitator Theobald, 1903. Napo (formerly Napo-Pastaza): Tena, Napo; Pastaza (formerly Napo-Pastaza): Shell-Mera, Arajuno (11). Guayas, Los Ríos, Napo (formerly Napo-Pastaza), Morona-Santiago (formerly Santiago-Zamora) $(10,17)$. No specific locality data (2).

90. Culex (Microculex) stonei Lane \& Whitman, 1943. Napo (formerly Napo-Pastaza): Tena, Napo; Pastaza (formerly Napo-Pastaza): Arajuno (11). Napo (formerly Napo-Pastaza) (10). No specific locality data (2).

Subgenus Phenacomyia Harbach \& Peyton, 1992

91. Culex (Phenacomyia) corniger Theobald, 1903. Guayas: Guayaquil, San Rafael (23). Guayas: Guayaquil and its surroundings (3). Guayas: Guayaquil, Chongón, Pascuales, Puná; Los Ríos: Vinces, Mocache, Quevedo; Esmeraldas: Esmeraldas, Limones; El Oro: Machala, Puerto Bolívar, Santa Rosa; Napo (formerly NapoPastaza): Tena, Ila, Napo; Pastaza (formerly Napo-Pastaza): Puyo, Shell-Mera, Mera, Arajuno (11). Guayas, El Oro, Manabí, Los Ríos, Esmeraldas, Napo (formerly Napo-Pastaza), and Morona-Santiago (formerly SantiagoZamora) $(10,17)$. No specific locality data (2).

Subgenus uncertain

92. Culex (Subgenus uncertain) aikenii Aiken \& Rowland, 1906. Nomen dubium (24). Los Ríos (10). No specific locality data (2).

93. Culex (Subgenus uncertain) ocellatus Theobald, 1903. Napo (formerly Napo-Pastaza): Tena, lla; Pastaza (formerly Napo-Pastaza): Arajuno (11). Napo (formerly Napo-Pastaza), Morona-Santiago (17).

Genus Haemagogus Williston, 1986

Subgenus Conopostegus Dyar, 1925

94. Haemagogus (Conopostegus) leucocelaenus (Dyar \& Shannon, 1924). Napo (formerly Napo-Pastaza): Tena, Ila, Napo (11). Napo (formerly Napo-Pastaza) (10).

95. Haemagogus (Conopostegus) leucotaeniatus (Komp, 1938). Esmeraldas: Quinindé (11). Esmeraldas, Manabí, and Pichincha (10). No specific locality data (2).

Subgenus Haemagogus Williston, 1986

96. Haemagogus (Haemagogus) albomaculatus Theobald, 1903. Guayas: El Salado (7). 
97. Haemagogus (Haemagogus) boshelli. Osorno-Mesa, 1944. Synonym: Haemagogus garciai Levi-Castillo, 1955. Esmeraldas: Isla de Changuaral $(12,25)$. No specific locality data (2).

98. Haemagogus (Haemagogus) equinus (Theobald, 1903). Guayas: El Salado (7). Later, Levi-Castillo (26) claimed that this species was absent from Ecuador.

99. Haemagogus (Haemagogus) janthinomys Dyar, 1921. Napo (formerly Napo-Pastaza), Morona-Santiago (formerly Santiago-Zamora) (27). Esmeraldas (26). No specific locality data (2).

100. Haemagogus (Haemagogus) panarchys Dyar, 1921. Guayas: Guayaquil and its surroundings (3). Guayas: Milagro (4). Guayas: Guayaquil, Guayaquil-Salinas road Km.3, Chongón or Colonche Mountain Range(28). Guayas: Guayaquil, Chongón, Progreso, Yaguachi, Milagro (11). Guayas, El Oro, Los Ríos, Manabí (10,12). "Chongón or Colonche Mountain Range" (actually includes the provinces of Guayas, Manabí, and Esmeraldas) (29). No specific locality data (2)..

101. Haemagogus (Haemagogus) soperi Levi-Castillo, 1955. Type locality: Ecuador, Los Ríos, Juan Montalvo (30). Esmeraldas; Manabí; El Oro: Santa Rosa (31). No specific locality data (2).

102. Haemagogus (Haemagogus) spegazzinii Brethés, 1912. Santo Domingo de los Tsáchilas (formerly part of Esmeraldas): Santo Domingo de los Colorados; Esmeraldas: Quinindé, Viche; Manabí: Santa Ana, Chone, Jama, Calceta; Napo (formerly Napo-Pastaza): Tena, Ila, Napo; Pastaza (formerly Napo-Pastaza): Puyo, Arajuno, Shell-Mera, Mera (11). Santo Domingo de los Tsáchilas: Santo Domingo de los Colorados (32).

Genus Limatus Theobald, 1901

103. Limatus andinus Levi-Castillo, 1954. Type locality: Ecuador, Los Ríos, Valencia (33). No specific locality data (2).

104. Limatus durhamii Theobald, 1901. Guayas: Guayaquil and its surroundings (3). Guayas: Guayaquil, Chongón, Progreso, Yaguachi, Milagro (11). Guayas, Los Ríos, Manabí, Esmeraldas, and El Oro (10).

105. Limatus guayasi Levi-Castillo, 1954. Type locality: Ecuador, Guayas, El Empalme (33). No specific locality data (2).

Genus Lutzia Theobald, 1903

Subgenus Lutzia Theobald, 1903

106. Lutzia (Lutzia) allostigma (Howard, Dyar \& Knab, 1915). No specific locality data (2).

107. Lutzia (Lutzia) bigoti Bellardi, 1862. No specific locality data (2).

Genus Mansonia Blanchard, 1901

Subgenus Mansonia Blanchard, 1901

108. Mansonia (Mansonia) humeralis Dyar \& Knab, 1916. Napo (formerly Napo-Pastaza): Tena; Pastaza (formerly Napo-Pastaza): Canelos, Arajuno (11). Napo (formerly Napo-Pastaza) (10). No specific locality data (2).

109. Mansonia (Mansonia) indubitans Dyar \& Shannon, 1925. El Oro: Machala, La Emerenciana, Bellavista, Santa Rosa; Manabí: Manta, Bahía de Caraquez, Chone, Calceta, Canuto (11). Guayas, El Oro, Manabí, Los Ríos, Esmeraldas (10). No specific locality data (2).

110. Mansonia (Mansonia) pseudotitillans Theobald, 1901. Guayas and Los Ríos (10). No specific locality data (2).

111. Mansonia (Mansonia) titillans (Walker, 1848). Guayas: Guayaquil (8). Guayas: Guayaquil, El Salado, Durán, Posorja; Los Ríos: Quevedo $(3,7,34)$. Guayas: Guayaquil, Samborondón, Yaguachi, Milagro; Esmeraldas:

Quinindé, Esmeraldas, Limones; Manabí: Jipijapa, Chone (11). No specific locality data (2).

112. Mansonia (Mansonia) wilsoni (Barreto \& Coutinho, 1944). Manabí (10). No specific locality data (2)

Genus Onirion Peyton \& Harbach, 2000 
113. Onirion personatum (Lutz, 1904). Santo Domingo de los Tsáchilas (formerly part of Esmeraldas): Santo Domingo de los Colorados; Esmeraldas: Quinindé, Viche (11). Manabí, Esmeraldas, Los Ríos, Guayas, and Pichincha (10). No specific locality data (2).

Genus Orthopodomyia Theobald, 1904

114. Orthopodomyia fascipes (Coquillett, 1906). Napo (formerly Napo-Pastaza): Tena (11). Guayas, Los Ríos, Napo (formerly Napo-Pastaza) (10). No specific locality data (2).

Genus Psorophora Robineau-Desvoidy, 1827

Subgenus Grabhamia Theobald, 1903

115. Psorophora (Grabhamia) cingulata Fabricius, 1805. Napo: Tena, Dos Ríos (35). No specific locality data (2).

116. Psorophora (Grabhamia) confinnis (Lynch Arribalzaga, 1891). Guayas, Manabí, Los Ríos(10). No specific locality data (2).

Subgenus Janthinosoma Lynch Arribálzaga, 1891

117. Psorophora (Janthinosoma) cyanescens (Coquillett, 1902). Napo (formerly Napo-Pastaza): Tena, Ila, Napo; Pastaza: (formerly Napo-Pastaza): Puyo, Mera, Shell-Mera, Arajuno (11). Napo (formerly Napo-Pastaza) (10). No specific locality data (2).

118. Psorophora (Janthinosoma) ferox (Humboldt, 1819). Guayas: Guayaquil and its surroundings (3,7). Napo (formerly Napo-Pastaza): Tena, Ila, Napo; Pastaza (formerly Napo-Pastaza): Mera, Shell-Mera, Arajuno; Santo Domingo de los Tsáchilas (formerly part of Esmeraldas): Santo Domingo de los Colorados; Esmeraldas: Quinindé, Viche (11). Guayas, El Oro, Manabí, Esmeraldas, Napo (formerly Napo-Pastaza) (10). No specific locality data (2).

119. Psorophora (Janthinosoma) lutzii (Theobald, 1901). Guayas, Manabí, Los Ríos, Esmeraldas (formerly NapoPastaza) (10). No specific locality data(2).

Subgenus Psorophora Robineau-Desvoidy, 1827

120. Psorophora (Psorophora) ciliata Fabricius, 1794. Napo (formerly Napo-Pastaza): Tena, lla, Napo (11). Manabí, Esmeraldas, Napo (formerly Napo-Pastaza) (10). No specific locality data (2).

Genus Sabethes Robineau-Desvoidy, 1827

Subgenus Peytonulus Harbach, 1991

121. Sabethes (Peytonulus) fabricii Lane \& Cerqueira, 1942. No specific locality data (2).

122. Sabethes (Peytonulus) identicus Dyar \& Knab, 1907. Manabí: Santa Ana, Chone, Calceta, Canuto, Eloy Alfaro, Flavio Alfaro, Jama, Portoviejo, Colón, Junín, Jipijapa (11). Guayas, Manabí, Los Ríos (10). No specific locality data (2).

Subgenus Sabethes Robineau-Desvoidy, 1827

123. Sabethes (Sabethes) bipartipes Dyar \& Knab, 1906. Guayas (Dyar 1925). Guayas: Guayaquil, Durán, Posorja $(3,7,8)$. Guayas: Milagro (4). Guayas: Guayaquil, Pascuales, Yaguachi, Milagro, Chongón, Progreso, Cerecita, Nobol, Durán, Balzar, Daule (11). Guayas, El Oro, Manabí, Los Ríos (10). No specific locality data (2).

124. Sabethes (Sabethes) cyaneus (Fabricius, 1805). Esmeraldas: Quinindé; Santo Domingo de los Tsáchilas (formerly part of Esmeraldas): Santo Domingo de los Colorados (11). Manabí (10). No specific locality data (2).

Subgenus Sabethoides Theobald, 1903

125. Sabethes (Sabethoides) chloropterus (von Humboldt, 1819). Guayas: Guayaquil and its surroundings (3). Guayas: Guayaquil, Chongón (11). Guayas, El Oro, Los Ríos, Manabí(10). No specific locality data (2). 
Genus Trichoprosopon Theobald, 1901

126. Trichoprosopon andinum Levi-Castillo, 1953. Described as andinus (36). Type locality: Ecuador, Cotopaxi, Macuchi (36). No specific locality data (2).

127. Trichoprosopon compressum Lutz, 1905. Santo Domingo de los Tsáchilas (formerly part of Esmeraldas): Santo Domingo de los Colorados; Esmeraldas: Quinindé (11). Guayas, Los Ríos, Manabí, and Esmeraldas (10). No specific locality data (2).

128. Trichoprosopon cotopaxense Levi-Castillo, 1953. Described as cotopaxensis. Changed to cotopaxense (37). Nomen dubium possible syn. Trichoprosopon digitatum \& Johnbelkinia ulopus (38).Provisionally accepted name (39). Nomina dubia (40). Type locality: Ecuador, Cotopaxi, Macuchi (36). No specific locality data (2)

129. Trichoprosopon digitatum (Rondani, 1848). Guayas: Guayaquil, Naranjal; El Oro: Machala (3,7). Guayas: Guayaquil, Chongón, Progreso, Tenguel, Puná; Santo Domingo de los Tsáchilas (formerly part of Esmeraldas): Santo Domingo de los Colorados; Esmeraldas: Quinindé (11). Guayas, Manabí, Esmeraldas, Pichincha, and Los Ríos (10). No specific locality data (2).

130. Trichoprosopon evansae Antunes, 1942. Napo (formerly Napo-Pastaza): Tena, lla (11). Napo (formerly NapoPastaza) (10). No specific locality data (2).

131. Trichoprosopon lanei (Antunes, 1937). Synonym: Goeldia lanei Antunes, 1937. Napo (formerly Napo-Pastaza): Tena, Ila, Napo; Pastaza (formerly Napo-Pastaza): Puyo (11). Napo (formerly Napo-Pastaza) (10). No specific locality data (2).

132. Trichoprosopon vonplesseni (Dyar \& Knab, 1906). Napo (formerly Napo-Pastaza): Tena (11). Napo (formerly Napo-Pastaza) (10,41). No specific locality data (2).

Genus Toxorhynchites Theobald, 1901

Subgenus Lynchiella Lahille, 1904

133. Toxorhynchites (Lynchiella) bambusicola Knight \& Rozeboom, 1946. No specific locality data (2).

134. Toxorhynchites (Lynchiella) haemorrhoidalis (Fabricius, 1787). No specific locality data (2).

135. Toxorhynchites (Lynchiella) haemorrhoidalis superbus (Fabricius, 1787). Guayas: Guayaquil and its surroundings (3). Guayas: Guayaquil, Chongón, Nobol, Puná, Tenguel (11). Guayas, Manabí, Los Ríos (10). No specific locality data (2).

136. Toxorhynchites (Lynchiella) hypoptes Knab, 1907. Guayas: Guayaquil and its surroundings (3). Guayas: Guayaquil, Chongón, Puná (11). Guayas, Manabí, Esmeraldas, and Los Ríos (10).No specific locality data (2).

137. Toxorhynchites (Lynchiella) theobaldi (Dyar \& Knab, 1906). No specific locality data (2).

138. Toxorhynchites aequatorianus Levi-Castillo, 1953. Nomen dubium (42). Type locality: Ecuador, Los Rios: Pichilingue (43). No specific locality data (2).

Genus Uranotaenia Lynch Arribálzaga, 1891

Subgenus Uranotaenia Lynch Arribálzaga, 1891

139. Uranotaenia (Uranotaenia) aequatorianna Levi-Castillo, 1953. Type locality: Los Ríos, Babahoyo (10). No specific locality data (2)

140. Uranotaenia (Uranotaenia) geometrica Theobald, 1901. Guayas: Guayaquil and its surroundings (3). Guayas: Guayaquil, Chongón, Nobol, Pascuales, Puna, Tenguel; El Oro: Machala, Santa Rosa, La Emerenciana, Tendales (11). Guayas, El Oro, Los Ríos, and Manabí (10). No specific locality data (2).

141. Uranotaenia (Uranotaenia) leucoptera (Theobald, 1907). Los Ríos (10). No specific locality data (2). 
142. Uranotaenia (Uranotaenia) lowii Theobald, 1901. Guayas: Guayaquil and its surroundings $(3,7)$. Bolívar (formerly part of Los Ríos): Balsapamba; Guayas: Guayaquil, Chongón, Nobol, Pascuales, Puna, Tenguel; El Oro: Machala, Pasaje, Santa Rosa, La Emerenciana, Bellavista; Manabí: Portoviejo, Manta, Chone, Santa Ana, Junín, Calceta, Tosagua, Bahía de Caraquez, San Vicente, Jipijapa, Paján; Esmeraldas: Esmeraldas, Quinindé, Río Verde, Táchina; Santo Domingo de los Tsáchilas: Santo Domingo de los Colorados (formerly part of Esmeraldas); Los Ríos: Babahoyo, Montalvo, Barreiro, Baba, Vinces, Mocache, Palenque, Jujan (11). Guayas, Los Ríos, Manabí, Esmeraldas (10). No specific locality data (2).

143. Uranotaenia (Uranotaenia) pulcherrima Lynch Arribálzaga, 1891. Guayas: Guayaquil and its surroundings (3). Los Rios and Guayas (10). No specific locality data (2).

144. Uranotaenia (Uranotaenia) sapphirina (Osten Sacken, 1868). Guayas: Guayaquil (8).Los Ríos and Guayas (10). No specific locality data (2).

Genus Wyeomyia Theobald, 1901

Subgenus Dendromyia Theobald, 1903

145. Wyeomyia (Dendromyia) complosa (Dyar, 1928). No specific locality data (2).

Subgenus Dodecamyia Dyar, 1918

146. Wyeomyia (Dodecamyia) aphobema Dyar, 1918. Synonym: Wyeomyia aphobema var. aequatorialis LeviCastillo, 1952. Napo (formerly Napo-Pastaza): near Tena (10,44)"mendeley":: "formattedCitation":"(10,44. No specific locality data (2).

Subgenus Hystatomyia Dyar, 1919

147. Wyeomyia (Hystatomyia) esmeraldasi (Levi-Castillo, 1955). Described as Phoniomyia esmeraldasi by LeviCastillo (1955). Type locality: Ecuador, Esmeraldas, Island of Changuaral, Ancón de Sardinas Bay (30). No specific locality data (2).

Subgenus Miamyia Dyar, 1919

148. Wyeomyia (Miamyia) codiocampa Dyar \& Knab, 1907. Manabí, Esmeraldas, Guayas, Los Ríos, and El Oro (10). No specific locality data (2).

Subgenus Nunezia Dyar, 1928

149. Wyeomyia (Nunezia) bicornis (Root, 1928). Pastaza (formerly Napo-Pastaza): Arajuno (11). Manabí, Esmeraldas, and Napo (formerly Napo-Pastaza) (10).

Subgenus Phoniomyia Theobald, 1903

150. Wyeomyia (Phoniomyia) lassalli (Bonne-Wepster \& Bonne, 1921). Napo (formerly Napo-Pastaza) (10). No specific locality data (2).

151. Wyeomyia (Phoniomyia) splendida Bonne-Wepster \& Bonne, 1919. Manabí, Esmeraldas, and Napo (formerly Napo-Pastaza) (10). No specific locality data (2).

Subgenus Wyeomyia Theobald, 1901

152. Wyeomyia (Wyeomyia) melanopus Dyar, 1919. No specific locality data (2).

153. Wyeomyia (Wyeomyia) scotinomus (Dyar \& Knab, 1907). Napo (formerly Napo-Pastaza): Tena (11). Manabí, Esmeraldas, Los Ríos, and Napo (formerly Napo-Pastaza) (10). No specific locality data (2).

Subgenus uncertain

154. Wyeomyia (Subgenus uncertain) aequatorianna Levi-Castillo, 1954. Type locality: Ecuador, Los Ríos, Hacienda Pichilingue (33). No specific locality data (2). 
155. Wyeomyia (Subgenus uncertain) amazonica Levi-Castillo, 1954. Type locality: Ecuador, Napo, Tena. Pastaza (33). No specific locality data (2).

156. Wyeomyia (Subgenus uncertain) chalcocephala Dyar \& Knab, 1906. No specific locality data (2).

157. Wyeomyia (Subgenus uncertain) flui (Bonne-Wepster \& Bonne, 1920). No specific locality data (2).

158. Wyeomyia melanocephala Dyar \& Knab, 1906. . Napo (formerly Napo-Pastaza): Tena, lla; Pastaza (formerly Napo-Pastaza): Arajuno (11). Manabí, Esmeraldas, Guayas, Los Ríos, Napo (formerly Napo-Pastaza) (10). No specific locality data (2).

\section{Literature cited}

1. Levi-Castillo R. Catálogo de los Anofelinos de la República del Ecuador. Guayaquil: Artes Gráficas Senefelder C.A.; 1945. p. 172.

2. Levi-Castillo R. Provisional list of the Culicidae, Simuliidae, Phlebotomus and Culicoides of Ecuador. Proceedings, Tenth International Congress of Entomology. 1958;3.

3. Campos FR. Estudios biológicos sobre los mosquitos de Guayaquil y alrededores. Revista del Colegio Nacional Vicente Rocafuerte. 1925;7:3-48.

4. Levi-Castillo R. Estudios sobre los Anofelinos de la región del Milagro. Revista de la Asociación de la Escuela de Ciencias Químicas. 1944;3.

5. Levi-Castillo R. El complejo pseudopunctipennis en el Ecuador (Diptera, Culicidae). Guayaquil: Imprenta de la Universidad de Guayaquil; 1944.

6. Levi-Castillo R. Anopheles pseudopunctipennis in the Los Chillos Valley of Ecuador. J Econ Entomol. 1945;38:385-8.

7. Campos FR. Estudios sobre la Fauna Entomológica del Ecuador. $2^{\circ}$ Dipteros Nematóceros: Fam. Culicidae (Mosquitos). Revista del Colegio Nacional Vicente Rocafuerte. 1922;18-30.

8. Campos FR. Un año a caza de criaderos de mosquitos por los pantanos de Guayaquil y sus alredores. Revista del Colegio Nacional Vicente Rocafuerte. 1924;17-27.

9. Levi-Castillo R. Un nuevo Anofelino de altura del Ecuador: Anopheles gomezdelatorreNN. Sp. Revista Ecuatoriana de Entomología y Parasitología. 1955;2:509-16.

10. Levi-Castillo R. Lista provisional y distribución de los mosquitos Culicinos del Ecuador. Revista Ecuatoriana de Entomología y Parasitología. 1953;34-45.

11. Levi-Castillo R. Vorläufige Liste der Stechmücken (Uranofaeniini, Toxorhynchitini, Culicini, Aedini und Sabethini) aus Ecuador (Diptera-Culicidae). Zeitschrift für Tropenmedizin und Parasitol. 1952;3:552-9.

12. Levi-Castillo R. The epidemiology of jungle yellow fever in coastal regions of Ecuador. Zeitschrift für Tropenmedizin und Parasitol. 1953;4:254-65.

13. Levi-Castillo R. Nota sobre la especie Aedes (Ochlerotatus) milleri Dyar, 1922, encontrada en Cuenca (Azuay), Ecuador, con la redescripción completa de la especie (Diptera-Culicidae). Transactions, Ninth International Congress of Entomology. 1952;1:181-5.

14. Levi-Castillo R. Notas sobre la fauna culicidiana de las Provincias de Azuay y Cañar en la Región Austral del Ecuador (Diptera-Culicidae). Revista Ecuatoriana de Entomología y Parasitología. 1954;2:39-50.

15. Levi-Castillo R. Una nueva especie de Culex procedente de la Provincia de Los Ríos, Ecuador: Culex (Carrollia) babahoyensis N. Sp. (Diptera-Culicidae). Revista Ecuatoriana de Entomología y Parasitología. 1953;1:91-4.

16. Levi-Castillo R. A new species of Culex from Ecuador. Proceedings of the Entomological Society of Washington. 1953;55:161-3. 
17. Levi-Castillo R. Lista provisional de los mosquitos Culex del Ecuador. Physis. 1949;20:190-3.

18. Levi-Castillo R. Observations on the Subgenus Phalangomyia of the Genus Culex in Ecuador with description of a new species (Diptera, Culicidae). Pacific Science 1953;7:187-92.

19. Levi-Castillo R. Nota sobre una especie del subgenero Phalangomyia del genero Culex encontrada en la Provincia del Azuay (Ecuador): Culex archegus Dyar 1929. Transactions, 9th International Congress of Entomology. 1952;1:901-4.

20. Levi-Castillo R. Dos especies nuevas de mosquitos ecuatorianos. Revista Ecuatoriana de Entomología y Parasitología. 1953;1:14-8.

21. Levi-Castillo R.Culex (Phalangomyia) azuayus N. Sp., un nuevo mosquito de altura del Ecuador. Revista Ecuatoriana de Entomología y Parasitología. 1954;2:263-71.

22. Levi-Castillo R. Studies on Culex fatigans in Guayaquil, Ecuador. Morphology of males in strains resistant and nonresistant to chlorinated hydrocarbon insecticides. Revista Ecuatoriana de Entomología y Parasitología. 1954;2:7-13.

23. Campos FR. Especies nuevas de insectos ecuatorianos. Revista del Colegio Nacional Vicente Rocafuerte. 1921;3:84-92.

24. Belkin JN.Culex (Melanoconion) aikenii (A. \& R., 1906) a nomen dubium; ocossa D. \& K., 1919 and panocossa Dyar, 1923 both valid. Mosq Syst Newsl. 1970;2:59-60.

25. Levi-Castillo R. Nueva división sistemática del género Haemagogus Williston 1896 y una nueva especie ecuatoriana: Haemagogus garciai, N. Sp. Revista Ecuatoriana de Entomología y Parasitología. 1955;2:359-66.

26. Levi-Castillo R. Notes on Ecuadorian Mosquitoes- Haemagogus equinus in Ecuador and further taxonomic notes on Uranotaenia Levi-Castillo 1953. Revista Ecuatoriana de Entomología y Parasitología. 1954;2:83-8.

27. Levi-Castillo R. Los mosquitos del género Haemagogus-Williston, 1896 en América del Sur. Cuenca: Editorial "Don Bosco"; 1951. p. 77.

28. Levi-Castillo R. Notas sobre Haemagogus panarchys Dyar, 1921 (Diptera, Culicidae). Revista de Entomología. 1949;20:165-71.

29. Levi-Castillo R. The Haemagogus of South America. Revista Ecuatoriana de Entomología y Parasitología. 1954;2:269-302.

30. Levi-Castillo R. Phoniomyia esmeraldasi, a new mosquito from Ecuador. Revista Ecuatoriana de Entomología y Parasitología. 1955;2:389-92.

31. Levi-Castillo R. Haemagogus soperi N. Sp. mosquito transmisor de Fiebre Amarilla Selvática en el Ecuador (Diptera-Culicidae). Revista Ecuatoriana de Entomología y Parasitología. 1955;2):479-85.

32. Levi-Castillo R. Die Epidemiologie des Buschgelbfiebers in der Küstenebene von Ecuador. Z Tropenmed Parasitol. 1953;4:254-65.

33. Levi-Castillo R. Cuatro especies nuevas de Sabethini del Ecuador (Diptera--Culicidae). Revista Ecuatoriana de Entomología y Parasitología. 1954;2:247-60.

34. Campos FR. Estudios Entomológicos en el Ecuador (Mosquitos). Revista del Colegio Nacional Vicente Rocafuerte. 1921;5.

35. Levi-Castillo R. Aedes garciai N. Sp., un aedino nuevo para la fauna ecuatoriana.- Lanesia, nuevo subgénero de Aedes. Revista Ecuatoriana de Entomología y Parasitología. 1953;1:101-9.

36. Levi-Castillo R. Dos especies nuevas de mosquitos de la sierra ecuatoriana (Diptera-Culicidae). Revista Ecuatoriana de Entomología y Parasitología. 1953;1(4):63-70. 
37. Stone A. A synoptic catalog of the mosquitoes of the world, supplement III. (Diptera: Culicidae). Catálogo sinóptico de los zancudos del mundo, suplemento IV (Diptera: Culicidae). Proceedings of the Entomological Society of Washington. 1967;69:197-224.

38. Zavortink T. The new sabethine genus Johnbelkinia and a preliminary reclassification of the composite genus Trichoprosopon. Contributions of the American Entomological Institute. 1979;17:1-61.

39. Bisby F, Roskov Y, Orrell T, Niocolson D, Paglinawan L, Bailly N, et al. Species 2000 \& ITIS Catalogue of Life: 2009 Annual Checklist. http://www.catalogueoflife.org/annual-checklist/2009/

40. Clark JW, Linton Y-M, Pecor JE, Pecor D, Stoffer J, Motoki M, et al. Walter Reed Biosystematics Unit [Internet]. 2016 [cited 2016 Mar 16]. Available from: http://www.wrbu.org

41. Lane J. Neotropical Culicidae. Volume II - Tribe Culicini, Deinocerites, Uranotaenia, Mansonia, Orthopodomyia, Aedemoyia, Aedes, Psorophora, Haemagogus, tribe Sabethini, Trichoprosopon, Wyemoyia, Phoniomyia, Limatus and Sabethes. Vol. II. Sao Paulo, Brazil: University of São Paulo; 1953. p. 553-1112.

42. Stone A, Knight KL, Starcke H. A Synoptic Catalog of the Mosquitoes of the World (Diptera, Culicidae). Washington, D.C.: Entomological Society of America, Thomas Say Foundation; 1959. p. 358.

43. Levi-Castillo R. Toxohrynchites aequatorianus n. sp., especie nueva de Toxorhynchites hallada en Pichilingue, Los Ríos Ecuador (Diptera-Culicidae). Revista Ecuatoriana de Entomología y Parasitología. 1953;1:71-9.

44. Levi-Castillo R. Wyemoyia (Wyeomyia) aphobema var. aequatorialis var. n., a new sabethine mosquito from Ecuador (Diptera: Culicidae). Proceedings of the Royal Entomological Society of London. 1952;21:130-3. 